\title{
Assessment of alternative draw solutions for optimized performance of a closed-loop osmotic heat engine
}

\author{
Kerri L. Hickenbottom ${ }^{1,2}$, Johan Vanneste ${ }^{1}$, and Tzahi Y. Cath ${ }^{1}{ }^{*}$ \\ ${ }^{1}$ Colorado School of Mines, Golden, CO, USA \\ ${ }^{2}$ Humboldt State University, Arcata, CA, USA
}

* Corresponding author: e-mail: tcath@mines.edu; phone: (303) 273-3402; fax: (303) 273-3413

A manuscript prepared for possible publication in

Journal of Membrane Science

September 2015 


\begin{abstract}
Osmotic power harnesses the energy of mixing between high and low salinity streams. The osmotic heat engine (OHE) is a closed-loop, membrane-based power generation cycle that couples pressure retarded osmosis (PRO), an osmotically driven membrane process, with a thermal separation process. In this investigation, membrane distillation (MD), a thermally driven membrane process, was used. High power density in PRO is essential to minimize equipment costs and parasitic pumping losses. Likewise, high water flux is needed in MD to efficiently reconcentrate the diluted draw solution from the PRO process and minimize equipment costs. In this study, several ionic organic and inorganic draw solutions were evaluated as working fluids in the OHE. Their performance was assessed in terms of PRO power density and reverse solute diffusion, and MD water flux and thermal efficiency. Potential pore wetting of the MD membrane was also evaluated. The working fluids were also assessed in terms of their potential for equipment corrosion. Results indicate that sodium formate and $\mathrm{CaCl}_{2}$ outperform $\mathrm{NaCl}$ (commonly used PRO draw solution) in terms of PRO power density and reverse solute diffusion, and that $\mathrm{LiCl}$ and $\mathrm{CaCl}_{2}$ outperform $\mathrm{NaCl}$ in terms of $\mathrm{MD}$ water flux. Furthermore, there were no signs of MD membrane wetting, even at high feed concentrations. Results were used to perform an economic analysis and make future recommendations on the most suitable working fluid for the OHE. Of the select salts, $\mathrm{CaCl}_{2}, \mathrm{MgCl}_{2}$, sodium propionate, and $\mathrm{LiCl}$ resulted in the lowest $\mathrm{OHE}$ electricity generation costs and had the lowest potential for corrosion.
\end{abstract}

Keywords: Osmotic power; draw solutions; pressure retarded osmosis; membrane distillation; energy-water nexus 


\section{Introduction}

Pressure retarded osmosis (PRO) is an osmotically driven membrane process that harnesses the energy of mixing between high and low salinity streams to produce mechanical energy [1]. In PRO, water permeates via osmosis through a semi-permeable membrane from a low concentration feed stream into a high concentration draw solution, thus the permeate stream becomes pressurized and dilutes the draw solution. For PRO to produce net energy, the hydraulic pressure of the draw solution is lower than the osmotic pressure difference between the draw solution and the feed, and as a result, the net driving force for transport of water (permeate stream) is still from the feed to the draw solution. The energy in the pressurized, diluted draw solution can then be converted into electrical energy via a turbine-generator set. From its original concept, most studies investigated PRO in open-loop configurations (Fig. 1a), including stand alone PRO for energy generation from mixing of low concentration (e.g., river water or wastewater) and high concentration waters (e.g., seawater, Dead Sea water, or Great Salt Lake water) [2-4] or coupled RO-PRO for low-energy desalination [5, 6]. However, several factors inhibit open loop PRO process performance and economics, including feed water pre-treatment, membrane fouling, and inconsistent solution chemistries and temperatures [7-9].

Another PRO configuration, also proposed by Loeb [10], is a closed-loop PRO system (Fig. 1b). In this system, the diluted draw solution from the PRO process is regenerated with a thermal separation process (e.g., distillation column) that utilizes low-grade heat from natural or industrial processes. The thermal process produces a concentration draw solution and a deionized water stream, which are then used again in the PRO process. McGinnis et al. investigated this closed-loop configuration, naming it an Osmotic Heat Engine (OHE) [11] —in their first investigation they used a novel, thermolytic ammonia bicarbonate draw solution. Recently, another configuration of this system that couples PRO with membrane distillation (MD) was proposed (Fig. 1c) [12]. The main benefit of this configuration is that compared to thermal distillation processes, MD can operate at lower temperatures and can potentially have lower capital costs [13].

MD is a thermally driven membrane process in which the driving force is the partial vapor pressure difference (temperature and concentration dependent) across the membrane. In direct contact MD (DCMD), a warm feed stream (e.g., concentrated brine) and a cooler distillate 
stream (e.g., fresh water) are separated by a microporous, hydrophobic membrane [14]. Water evaporates from the feed stream at the feed-pore interface on the feed side of the membrane, diffuses through the membrane pores, and ultimately condenses into the distillate stream on the distillate side of the membrane. One of the main requirements of the MD process is that the membrane remains hydrophobic and no pore wetting occurs. Pore wetting of the MD membrane lowers rejection and process efficiency.

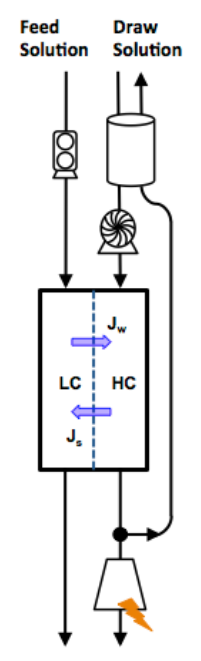

(a)

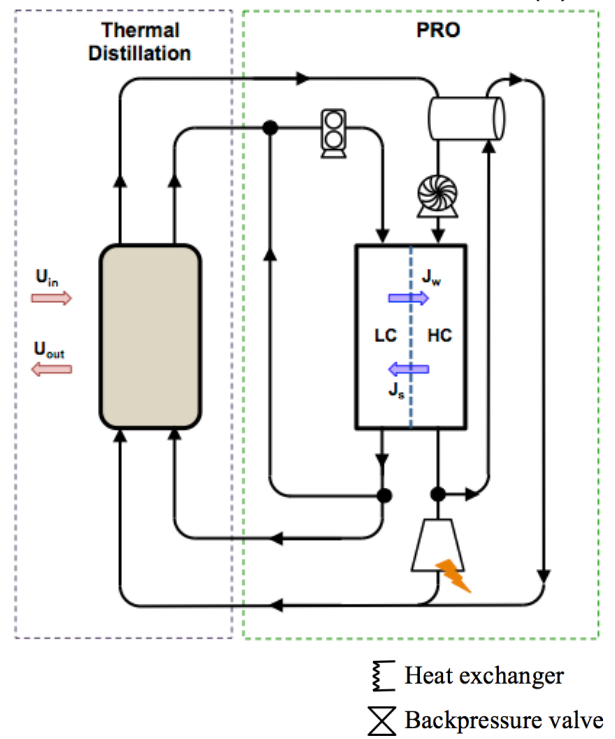

(b)

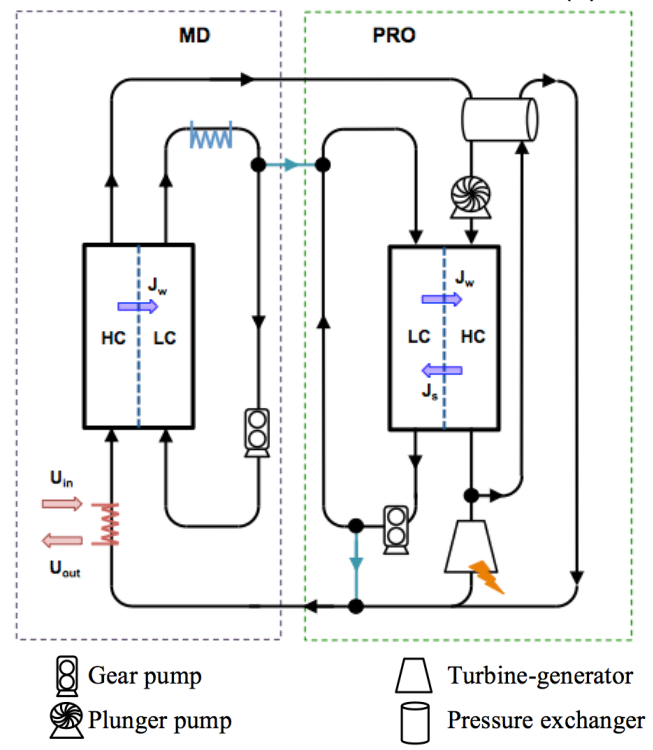

Figure 1. Basic configurations of PRO, including (a) open-loop PRO, (b) closed-loop PRO with thermal distillation for regeneration of the draw solution, and (c) closed-loop PRO with MD for reconcentration of the draw solution. $U$ is heat flow, $H C$ is high concentration, $L C$ is low concentration, $J_{w}$ is water flux, and $J_{s}$ is salt flux.

The closed-loop OHE has several major benefits over the open-loop PRO. The OHE allows for control of solution chemistries and temperatures. Because impurities are not introduced into the system, the potential for membrane fouling is reduced and the need for frequent chemical cleaning or membrane backwashing is eliminated. The OHE system can use low-grade heat emitted from industrial processes, which increases energy utilization-industrial processes account for nearly $30 \%$ of the total U.S. energy demand, of which $20-50 \%$ of the energy consumed is lost as waste heat in the form of hot exhaust gases, cooling water, and radiant heat from hot equipment surfaces and other heated products [15]. Therefore, the OHE can be colocated with existing power plants (e.g., traditional power plants or geothermal power plants) or 
other industrial processes emitting low-grade heat (e.g., chemical processing plants, cement plants, breweries, etc.).

Although the closed-loop PRO system offers many benefits, there are several barriers that hinder further development of the OHE. Primarily, both MD and PRO are relatively new membrane processes and their integration is not fully studied or understood. For example, high power density of the PRO membrane is essential to maximize process efficiency and minimize capital and operating costs of the OHE. Likewise, high separation efficiency and low potential for membrane wetting is needed in MD to reconcentrate the diluted draw solution from the PRO process. Several commercially available forward osmosis (FO) membranes have been investigated for use in PRO, and only a few of these membranes exhibited high water permeability, selectivity, and mechanical stability [16]. Because of non-ideal conditions in the PRO membrane, reverse permeation of solutes from the draw solution into the feed stream occurs (referred to as reverse solute flux (RSF)). As solute accumulates in the membrane support structure (referred to as internal concentration polarization (ICP)), the osmotic driving force in PRO is reduced [17] and can be detrimental to OHE performance. To maintain a high osmotic driving force in the OHE, a portion of the PRO feed stream has to be bled to the MD feed stream for recovery of solutes and control of PRO feed chemistry (Fig. 1c). The additional loading on the MD process will increase the amount of membrane area, pumping energy, and electricity generation costs of the $\mathrm{OHE}$.

Typically, $\mathrm{NaCl}$ is used as the standard draw solution in osmotically driven membrane processes [18]. Although $\mathrm{NaCl}$ is abundant and inexpensive, compared to other salts, it has higher RSF in osmotically driven membrane processes [19, 20]. Several studies have investigated the use of other inorganic and organic salts for use in FO [21-23]. McCutchoen et al. proposed a novel ammonia-carbon dioxide draw solution for use in FO [24, 25], which was later investigated in the OHE [11]. Although ammonium bicarbonate is highly soluble and has high osmotic pressures, high RSF of ammonia hinders efficient utilization of this draw solution [19]. Achilli et al. investigated the use of different inorganic draw solutions for use in FO-RO hybrid systems [19]. Their study established a protocol for selection of optimal draw solutions in FO and recognized that ICP strongly depends on draw solution diffusivity. These results were further confirmed by Zhao et al. [26]. Bowden et al. conducted a similar study with ionic inorganic and organic draw solutions in FO and found that organic salts with larger cations experience lower 
RSF [19, 27]. More recently, studies have aimed at engineering new and mixed draw solutions $[20,28,29]$. Engineered draw solutions combine the effects of high water permeation and low RSF, which are two important performance parameters in both open and closed-loop osmotically driven membrane processes. The addition of small amounts of chemical surfactants in draw solutions has been investigated in order to decrease RSF and increase process performance [28]. However, the use of surfactants, alcohols, and other organic solutes that have low surface tension is not favourable in MD because it increases the potential for membrane wetting [30].

Highly soluble ionic organic and inorganic salts are expected to increase PRO power densities; however, the RSF in PRO and the water flux in MD of these highly concentrated draw solutions needs to be experimentally verified. Although few studies have evaluated the potential of different draw solutions in PRO, the regeneration efficiency of these draw solutions using MD has not been investigated [11,31]. Therefore, the main objective of this study was to evaluate the performance of different ionic organic and inorganic salts in PRO and MD, and their potential as working fluids in the OHE. Experimental results were used to perform an economic analysis and make future recommendations on working fluids most suitable for the OHE. Results from this study can be useful for identifying ideal working fluids for other closed-loop membrane based processes such as closed-loop FO-MD.

\section{Theory}

Several transport phenomena govern water flux, solute flux, and power density in PRO. These include external concentration polarization (ECP), ICP, and RSF. Similarly, MD water flux is governed by several phenomena, including temperature and concentration polarization (TP and CP), heat and mass transfer resistances across the membrane, and membrane wetting.

\subsection{PRO}

The driving force for PRO is the osmotic pressure gradient between a low concentration feed and high concentration draw solution stream. In its simplest form, Eq. 1 is the general equation used to describe water flux $\left(J_{w}\right)$ in PRO:

$$
J_{w}=A(\Delta \pi-\Delta P)
$$


where, $A$ is the water permeability coefficient (membrane specific), $\Delta \pi$ is the osmotic pressure difference across the membrane, and $\Delta P$ is the hydraulic pressure difference across the membrane. However, several transport phenomena impede water flux in PRO, including ICP, ECP, and RSF (Figure 2). As water permeates from the low concentration feed to the high concentration draw solution, the draw solution at the draw solution-membrane interface becomes diluted and the osmotic pressure driving force across the membrane declines-this is referred to as ECP. Similarly, as solutes diffuse from the high concentration draw solution to the low concentration feed stream, they accumulate in the membrane porous support structure (described as ICP). ICP in PRO is more severe than ECP, which is considered negligible [3, 17, 32, 33].

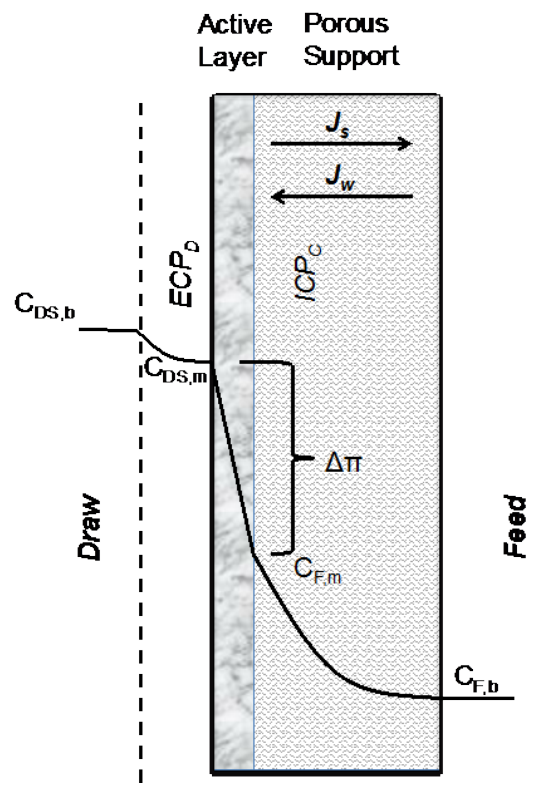

Figure 2. Schematic of concentration profiles at the PRO membrane. $J_{w}$ is water flux, $J_{s}$ is salt flux, $\Delta \pi$ is the osmotic pressure difference across the membrane, $C_{D S, b}$ is the bulk draw solution concentration, $C_{D S, m}$ is the draw solution concentration at the membrane, $C_{F, b}$ is the bulk feed concentration, $C_{F, m}$ is the feed concentration at the membrane, $\mathrm{ECP}_{\mathrm{D}}$ is the dilutive external $\mathrm{CP}$, and $\mathrm{ICP}_{\mathrm{C}}$ is the internal concentrative $\mathrm{CP}$.

ICP and ECP describe the severity of polarization - they can be calculated from film theory [32, 34] (Eq. 2 and 3, respectively), and the closer the moduli are to unity, the lesser the degree of polarization:

$$
\frac{\pi_{F, m}}{\pi_{F, b}}=\exp \left(J_{w} \frac{S}{D}\right)
$$




$$
\frac{\pi_{D S, m}}{\pi_{D S, b}}=\exp \left(-\frac{J_{w}}{k}\right)
$$

where $S$ is the structural parameter (membrane specific and defined by support layer thickness times pore tortuosity, divided by support layer porosity), $D$ is the diffusion coefficient of the draw solution solute, and $k$ is the mass transport coefficient of the draw solution solute in the draw solution flow channel. Yip et al. further expanded the general equation for water flux to include the effects of ICP, ECP, and RSF on PRO water flux [35]:

$$
J_{w}=A\left\{\frac{\pi_{D S, b} \exp \left(-\frac{J_{w}}{k}\right)-\pi_{F, b} \exp \left(J_{w} \frac{S}{D}\right)}{1+\frac{B}{J_{w}}\left[\exp \left(J_{w} \frac{S}{D}\right)-\exp \left(-\frac{J_{w}}{k}\right)\right]}-\Delta P\right\}
$$

where $\pi_{D S, b}$ is the osmotic pressure of the bulk draw solution, $\pi_{F, b}$ is the osmotic pressure of the bulk feed stream, and $B$ is the salt permeability coefficient (membrane and solute specific). The mass transport coefficient is a function of channel geometry and draw solution viscosity, density, and solute diffusivity [3, 32, 36]:

$$
k=\frac{S h D}{d_{h}}
$$

where, $S h$ is the Sherwood number and $d_{h}$ is the hydraulic diameter of the flow channel. For a spacer-filled channel, the flow regime becomes turbulent at relatively low Reynolds numbers (Re < 50) [36-38], and the following correlation can be used to calculate the Sherwood number [36]:

$$
S h=0.2 R e^{0.57} S c^{0.40}
$$

where Sc is the Schmidt number. The Schmidt number is the ratio of the kinematic viscosity to the solute diffusivity $(S c=v / D)$. The methodology for calculating the Reynolds number for a spacer filled channel can be found elsewhere [36].

$A, B$, and $S$ are inherent properties specific to the membrane, and they can be determined experimentally [18]. The ratio of $S$ to $D$ is defined as the solute resistivity for diffusion within the 
porous support layer $(K=S / D)$ and is a measure of the effect of ICP on water flux-the smaller $K$, the more severe the effects of ICP on water flux [19, 32]. The water permeability and salt permeability coefficients describe how well water and solutes permeate through the membrane, respectively. Therefore, membranes with high permeability and selectivity (aka permselectivity), and low structural parameter are desirable in osmotically driven membrane processes [3, 32, 35, 39].

Power density in PRO is a measurement of the energy that can potentially be generated per membrane area, and can be determined experimentally by multiplying the water flux by the hydraulic pressure in the draw solution (Eq. 7):

$$
W=J_{w} \Delta P
$$

Theoretically, the maximum power density in PRO (determined by differentiating Eq. 7 with respect to $\Delta P$ ) is reached when the applied pressure is half the osmotic pressure of the draw solution [33]. Non-ideal conditions in the PRO membrane and concentration difference across the membrane give rise to RSF, which can be calculated using Eq. 8 when expanded to include the effects of ICP and ECP:

$$
J_{S}=B\left\{\frac{C_{D S, b} \exp \left(-\frac{J_{w}}{k}\right)-C_{F, b} \exp \left(J_{w} \frac{S}{D}\right)}{1+\frac{B}{J_{w}}\left[\exp \left(J_{w} \frac{S}{D}\right)-\exp \left(-\frac{J_{w}}{k}\right)\right]}\right\}
$$

\section{2. $\mathrm{MD}$}

Water flux in MD is proportional to the partial vapor pressure (PVP) difference of the feed and distillate streams $\left(\Delta P_{v}\right)$ at the membrane-liquid interfaces (Eq. 9):

$$
J=C \Delta P_{v}
$$

The membrane permeation coefficient $(C)$ is a function of the temperature, pressure, membrane material, and membrane structure (i.e., porosity, tortuosity, and thickness). In many cases, for a given membrane, the membrane permeation coefficient can be approximated as being constant $[14,40]$. The PVP difference is dependent on the temperature and composition of 
the solutions. Higher solution temperatures result in higher VP, while higher solution concentrations result in lower PVP.

Several phenomena limit MD water flux and process efficiency. These include mass transfer resistance and heat conductance of the membrane, concentration polarization, temperature polarization, and membrane wetting [14, 41, 42]. A schematic of the concentration and temperature profiles and heat and water flux in MD is illustrated in Figure 3.

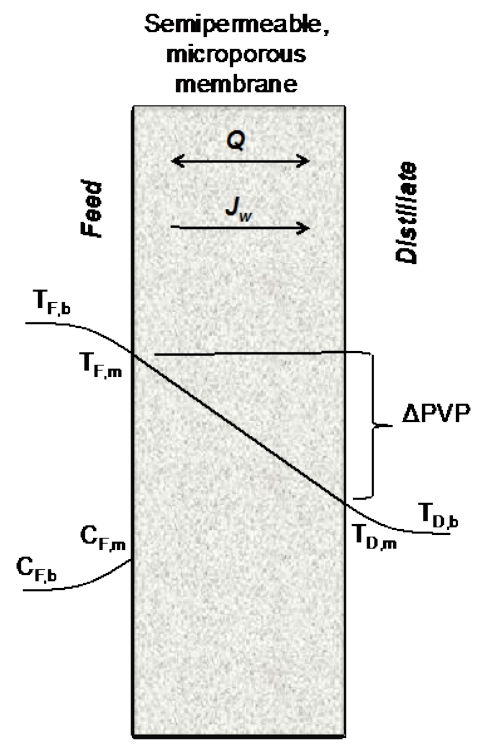

Figure 3. Schematic of temperature and concentration profiles across the MD membrane. $Q$ is the heat flux, $\Delta T$ is the transmembrane temperature, $C_{F, b}$ is the bulk feed concentration, $C_{F, m}$ is the feed concentration at the membrane surface, $T_{F, b}$ is the bulk feed temperature, $T_{F, m}$ is the feed temperature at the membrane surface, $T_{D, b}$ is the bulk distillate temperature, and $T_{D, m}$ is the distillate temperature at the membrane surface.

In DCMD, the membrane acts as a heat transfer interface between the feed and distillate streams. The temperature at the feed membrane interface is lower than in the bulk feed solution and the temperature at the distillate membrane interface is higher than in the bulk distillate stream, thus reducing the driving force for mass transport through the MD membrane. This phenomenon is termed temperature polarization (TP) and is expressed in Eq. 10:

$$
T P=\frac{T_{F, m}-T_{D, m}}{T_{F, b}-T_{D, b}}
$$


where $T_{F, b}$ and $T_{D, b}$ are the feed and distillate temperatures of the bulk streams, respectively, and $T_{F, m}$ and $T_{D, m}$ are the feed and distillate temperatures at the membrane interface, respectively. Because of heat transfer resistance, especially conductive heat loss in DCMD, the TP ratio is less than 1. Likewise, as water evaporates at the feed membrane interface and water vapor diffuses through the membrane pores, the concentration at the feed membrane interface increases; like in PRO, this phenomenon is referred to as ECP. Both ECP and TP are affected by cross flow velocity and solution viscosity and density. Generally, the effects of ECP in MD of dilute streams are considered negligible [41]; however, it can substantially impact the performance of MD at high feed salt concentration.

Several phase changes occur during the MD process, and heat transfer resistances across the boundary layers are often the rate-limiting step [14]. Heat transfer resistances in MD occur at the feed-membrane interface (vapor transfer), distillate-membrane interface, and the membrane barrier itself (conductive heat transfer). Therefore, the total heat transfer across the membrane is the sum of the vapor transfer and conductive heat transfer. Thermal efficiency in MD is defined as the ratio of latent heat of vaporization to the total (latent and conduction) heat, and is used to describe heat losses in MD [43]:

$$
\eta=\frac{J \Delta H_{v}}{J \Delta H_{v}+\frac{k_{m}}{\delta}\left(T_{f, m}-T_{p, m}\right)}
$$

The thermal efficiency can be determined experimentally by performing an energy balance on the distillate channel:

$$
\eta=\frac{m_{p} h_{f g}}{\left(m_{d, l n}+m_{p}\right) c_{p, d} T_{d, o u t}-m_{\dot{d}, \imath n} c_{p, d} T_{d, i n}}
$$

where, $m_{p}$ is the mass flow rate of the permeate stream, $h_{f g}$ is the latent heat of vaporization of water in the MD feed stream, $m_{d, i n}$ is the mass flow rate of the influent distillate stream, $c_{p, d}$ is the average heat capacity of the distillate stream, and $T_{d, \text { in }}$ and $T_{d, \text { out }}$ are the inlet and outlet temperatures of the distillate stream, respectively. The energy balance is performed on the distillate channel because the heat losses to the environment from the distillate channel are lower than the heat losses from the feed channel. 
Heat transfer efficiency in MD can be reduced by decreasing flow rates and operating with thicker membranes [41]; however, operating at high flow rates increases pumping demands, and the use of thicker membranes increases mass transfer resistance within the membrane [44, 45]. Pore wetting of the MD membrane lowers salt rejection, and impairs the integrity of the membrane (i.e., loss of hydrophobicity). To limit membrane wetting, the pressure at the feedmembrane interface must be less than the entry pressure at the membrane surface [14]; therefore, working fluids, namely organic solutes and alcohols, with low surface tensions must be avoided.

\section{Materials and methods}

PRO and MD bench-scale experiments were performed. Select salts were used as PRO draw solutions and MD feed solutions. A system model was developed to evaluate their suitability as working fluids in the OHE.

\subsection{Membranes}

A commercial, semipermeable, flat-sheet FO membrane was acquired from Hydration Technology Innovation (HTI) (Albany, OR) and a hydrophobic microporous membrane was acquired from 3M (St. Paul, MN). The FO membrane is a polyamide-based, thin-film composite (TFC) and was used for PRO. The 3M MD membrane is made of polypropylene (PP) and it has a nominal pore size of 0.2 microns.

\subsection{Membrane cells}

A modified, stainless steel SEPA-CF II cell (GE Water \& Process Technologies, Trevose, PA) was used for the PRO experiments. The cell has an active membrane surface area of 139 $\mathrm{cm}^{2}$, with a feed and draw solution flow channel depth of $1 \mathrm{~mm}$. The cannel length and width were approximately $14 \mathrm{~cm}$ and $10 \mathrm{~cm}$, respectively. The feed and draw solution spacers were taped to the cell to prevent tearing of the membranes at the edges of the channels. Taping of the spacers decreased the effective membrane surface area to $124 \mathrm{~cm}^{2}$.

A similar modified SEPA-CF cell made of acrylic plastic was used for the MD experiments. Nitrile rubber gaskets were used to form flow channels, approximately $2 \mathrm{~mm}$ deep, on each side of the membrane. Turbulence enhancing spacers were placed in the flow channels to reduce 
temperature polarization effects, increase water flux [46], and ensure that the membrane lay flat and centered in the cell.

\subsection{Spacers}

Tricot warp knit (Hornwood Inc., Lilesville, NC) and non-woven extruded mesh spacers were used in these experiments (Figure 4). The tricot spacers used have 20 carrier channels per inch (0.68 mm wide) and are $0.5 \mathrm{~mm}$ thick. Two types of extruded mesh spacers were used. The one used for PRO has an inner filament length and filament diameter of 2.5 and $0.5 \mathrm{~mm}$, respectively, and the one used for $\mathrm{MD}$ has an inner filament length and filament diameter of 3.5 and $1.25 \mathrm{~mm}$, respectively. Spacer configurations used in MD and PRO are illustrated in Figure 5. Two tricot spacers, positioned at $45^{\circ}$ to the flow were used in the PRO feed channel, and one tricot spacer with one extruded mesh was used in the PRO draw solution channel. An extruded mesh spacer was used in the MD distillate and feed solution channels.

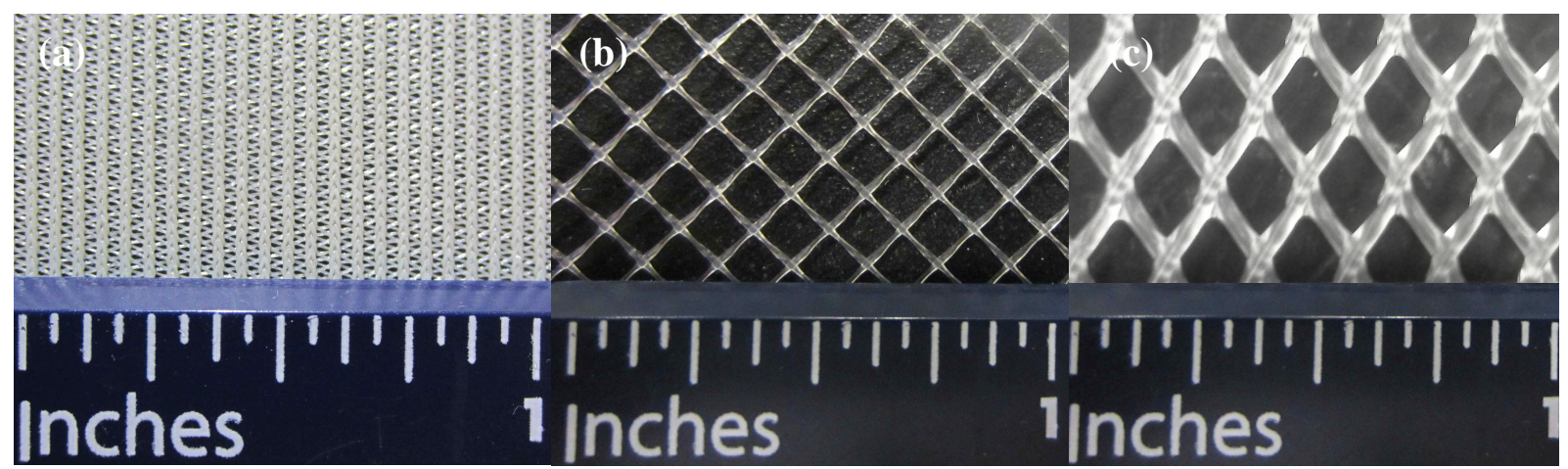

Figure 4. Picture of the (a) 20-channel tricot PRO feed solution and draw channel spacer, (b) extruded mesh PRO draw channel spacer, and (c) extruded mesh MD feed solution and distillate channel spacer.

(a)

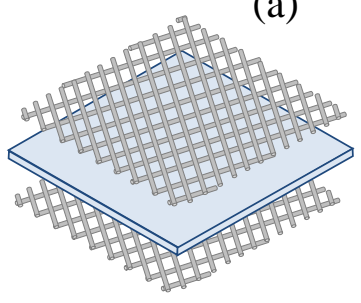

(b)

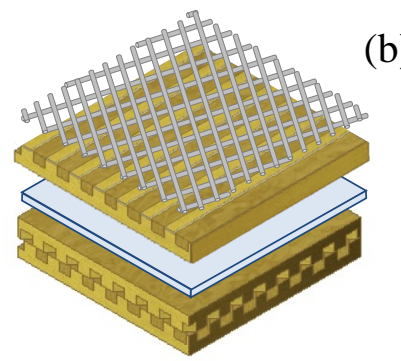

Figure 5. Spacer configurations for (a) MD and (b) PRO bench scale experiments. An extruded mesh spacer was used in the MD distillate and feed solution channels. Two tricot spacers, positioned at $45^{\circ}$ to the flow were used in the PRO feed channel, and one tricot spacer with one extruded mesh was used in the PRO draw solution channel. 


\subsection{Bench scale systems}

PRO and MD bench scale experiments were performed. Different working fluids were tested and their performance in PRO (water flux, RSF, and power density) and MD (water flux, thermal efficiency, and rejection) were investigated. A supervisory control and data acquisition (SCADA) system (LabVIEW, National Instruments, Austin, TX; and UE9-Pro, LabJack, Lakewood, CO) was used to control and record pressures, flow rates, temperatures, and feed and working fluid concentrations.

\subsubsection{PRO bench scale system}

A flow schematic of the PRO test unit is illustrated in Figure 6. The thermally insulted feed and draw solution reservoirs were connected to a gear pump (Micropump, Vancouver, WA) and a direct drive plunger pump (Cat Pumps, Minneapolis, MN), respectively, which circulated the two streams co-currently on the opposite sides of the membrane. In practice, the feed and draw solution would be circulated counter-currently; however, due to the small size of the test cell, operating in co-current mode has negligible effects on process performance. Echopod ultrasonic level sensors (FlowLine, Los Alamitos, CA) were installed on top of the feed and draw solution reservoirs to monitor the levels of fluids and calculate water flux. Pressure transducers (Omega Engineering, Stamford, CT) located at the inlets and outlets of the membrane cell monitored feed and draw solution channel pressure drops, and a proportional valve (Hass Manufacturing Co., Averill Park, NY) was used to control the hydraulic pressure in the draw solution flow channel. Toroidal conductivity sensors (Sensorex, Garden Grove, CA), located at the membrane cell outlets, were used to monitor and facilitate the control of the feed and draw solution concentrations. A peristaltic pump (McMaster-Carr, Chicago, IL) was used to dose the draw solution with concentrated brine and maintain constant draw solution concentrations during experiments. Stream temperatures were monitored with silicon crystal based sensors (LabJack, Lakewood, CO) and controlled with shell-and-tube heat exchangers.

The feed and draw solution flow rates and temperatures were kept constant at $0.5 \mathrm{~L} / \mathrm{min}$ and $30{ }^{\circ} \mathrm{C}$, respectively. Experiments were performed at draw solution hydraulic pressures of 2.1 MPa (300 psi). Changes in feed tank volume, feed stream conductivity, and membrane cell inlet and outlet pressures were used to calculate water flux, RSF, and feed channel pressure drop, 
respectively. Power density was calculated by multiplying the water flux by the draw solution inlet pressure. Specific RSF was determined by the ratio between the RSF and water flux $\left(J_{s} / J_{w}\right)$. PRO experiments were conducted for 150 min (thirty minute stabilization period, two hour data collection period). The PRO feed stream conductivity was closely monitored throughout the experiments, and was replaced with a new batch of deionized water once the conductivity reached 1,200 $\mu \mathrm{S} / \mathrm{cm}$ (500 mg/L NaCl) [3]. Feed and draw solution samples were collected for analysis at the beginning and end of the data collection period.

Although the HTI TFC membrane can operate at draw solution hydraulic pressures of up to 3.4 MPa (500 psi) before deformation [16], a lower draw solution pressure was chosen because most FO membrane manufacturers would not guarantee the membrane modules above $1.4 \mathrm{MPa}$ (200 psi) [5, 47]. Integrity tests were performed before and after each experiment to ensure that the membrane was not damaged. Membrane integrity tests were performed with a $50 \mathrm{mM} \mathrm{NaCl}$ draw solution and deionized water as the feed, and a draw solution hydraulic pressure of $2.1 \mathrm{MPa}$ (300 psi). The feed and draw solution flow rates and temperatures were kept constant at 0.5 $\mathrm{L} / \mathrm{min}$ and $30{ }^{\circ} \mathrm{C}$, respectively. Water flux and RSF were closely monitored to ensure that the membrane performance remained the same.
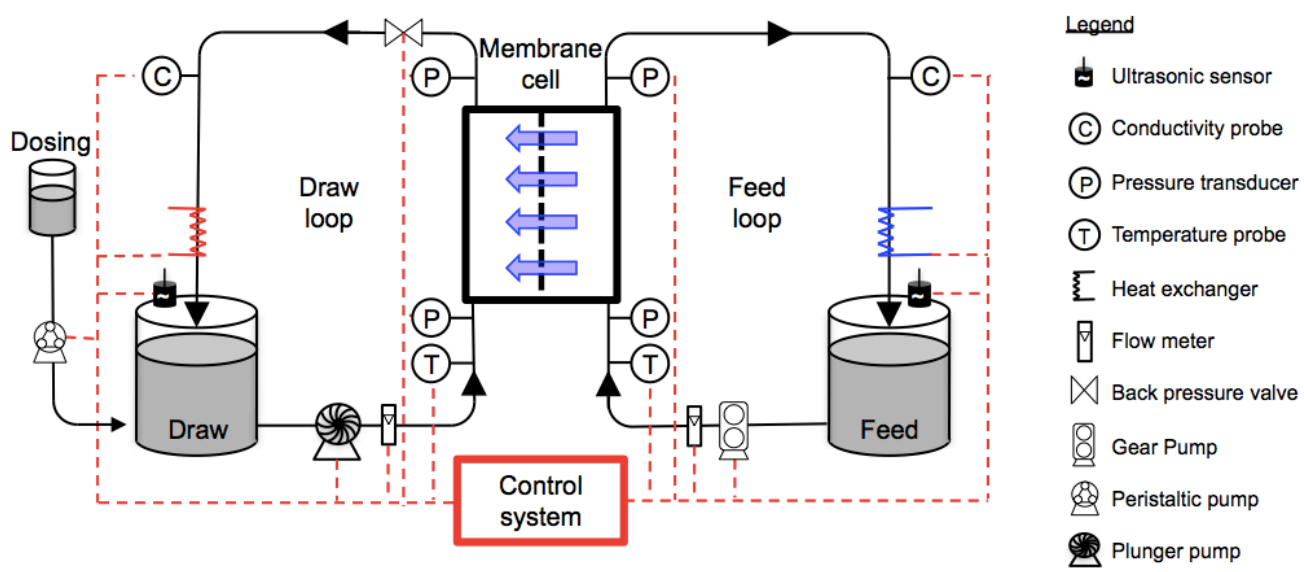

Figure 6. Flow diagram for the bench scale PRO system.

\subsubsection{Bench scale system}

A flow schematic of the DCMD test unit is illustrated in Figure 7. The thermally insulated feed (draw solution) and distillate stream reservoirs were connected to gear pumps (Micropump, Vancouver, WA), which circulated the two streams counter-currently on the opposite sides of the 
membrane. The distillate reservoir was positioned on an analytical balance to monitor the change in weight of the distillate, and calculate water flux. A toroidal conductivity sensor and graphite electrode conductivity probe, located at the membrane cell outlets, were used to monitor and facilitate the control of the distillate and feed solution concentrations. Experiments were conducted at constant feed solution concentrations having osmotic pressure of 17.4 MPa. The feed solution concentration was maintained constant by manually dosing the concentrated feed solution reservoir with deionized water. Stream temperatures were monitored and controlled with shell-and-tube heat exchangers. Heating and cooling reservoirs (Fisher Scientific, Pittsburg, PA) were used to maintain the distillate and feed solution at constant temperatures.
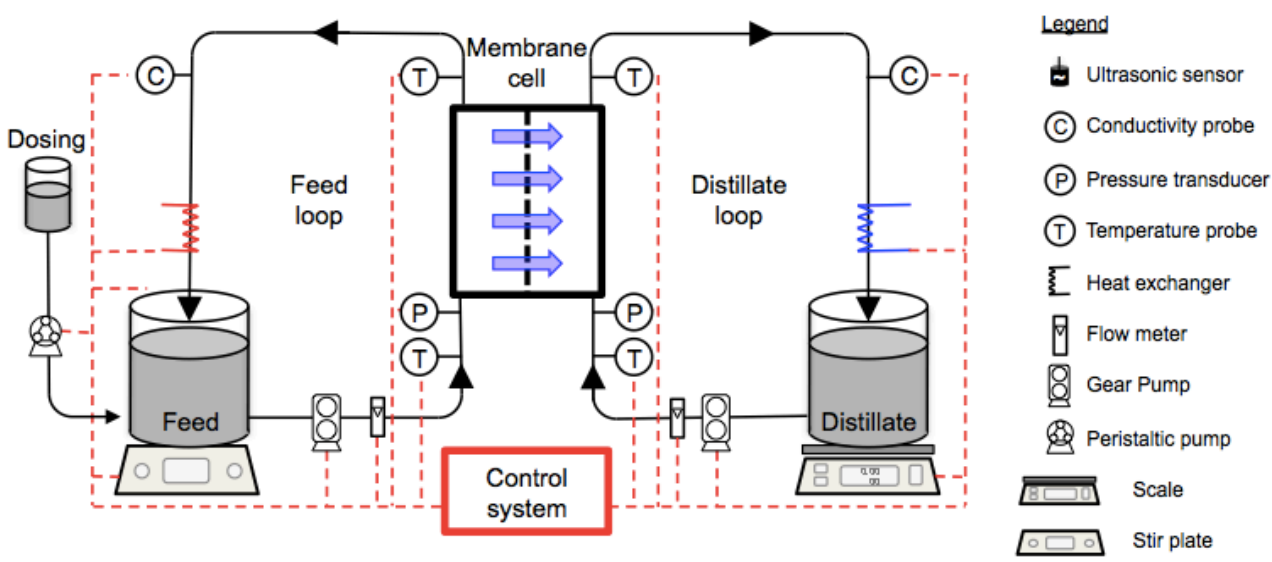

Figure 7. Flow diagram for the MD bench scale system.

The distillate and feed solution flow rates were kept constant at $1.0 \mathrm{~L} / \mathrm{min}$ ' and the temperatures of the distillate and feed solution kept at $24 \pm 2{ }^{\circ} \mathrm{C}$ and $56 \pm 1.6{ }^{\circ} \mathrm{C}$, respectively. Changes in distillate tank weight and conductivity were used to calculate water flux and salt rejection, respectively. MD experiments were performed for one hour (thirty minute stabilization period, 30 minute data collection period). Feed and distillate samples were collected for analysis at the beginning and end of the data collection period.

\subsection{Desktop screening process and solution chemistry}

Twenty-eight potential working fluids were initially screened for the OHE by evaluating their solubility in water, toxicity, osmotic pressure, and pH. OLI Stream analyzer software (OLI Systems, Inc, Morris Plains, NJ) was used to determine the osmotic pressure, PVP, diffusivities, 
viscosities, and $\mathrm{pH}$ of the select salts. Corrosion rates were determined with OLI studio Corrosion Analyzer (OLI Systems, Inc, Morris Plains, NJ). Solute diffusivities were calculated using a harmonic average of the diffusivity coefficients for the individual ions [48]. Salts that had osmotic pressures lower than $1 \mathrm{MPa}$ at saturation were excluded. The remaining working fluid candidates were then evaluated in terms of their hazardous materials identification (HMIS) codes. Similar to other studies, salts with an HMIS level higher than 2 were excluded [19, 27]. Alcohols were also excluded (high potential for wetting of MD membrane). The membranes used for PRO are stable at a pH range of 2 to 11 (specified by manufacture); therefore, solutions with pHs out of this range were not considered.

From the initial list of salts, 18 ionic inorganic and organic salts were identified as possible working fluids; however, because the objective of the OHE is to produce energy, salts with high osmotic pressures must be used (high osmotic pressures produce higher power densities). Therefore, an additional screening criteria was applied: at saturation, salts must have osmotic pressures equal or higher than that of $\mathrm{NaCl}$ at saturation ( 30 MPa). The additional screening criterion narrowed the list down to eight salts (Table 1). The salts were tested at concentrations equivalent to 17.4 MPa osmotic pressure (osmotic pressure of $3 \mathrm{M} \mathrm{NaCl}$ ), and deionized water was used as the PRO feed and MD distillate. Specific salt costs are for certified ACS grade salts with purities higher than 99\%, and were obtained from GFS Chemicals Inc. (Columbus, OH) and Univar USA, Inc. (City of Commerce, CA).

Table 1. Solubility, specific costs, and concentrations corresponding to $17.4 \mathrm{MPa}$ osmotic pressure (equivalent osmotic pressure for $3 \mathrm{M} \mathrm{NaCl}$ ) for eight potential OHE working fluids. Specific salt costs are bulk quotes from GFS Chemicals Inc., with the exception of $\mathrm{Na}(\mathrm{C} 2 \mathrm{H} 5 \mathrm{COO})$, which was referenced from Univar USA, Inc. The bulk salts are certified ACS grade, with purities $>99 \%$.

\begin{tabular}{|c|c|c|c|c|}
\hline \multirow[t]{2}{*}{ Working fluid } & \multirow{2}{*}{$\begin{array}{c}\text { Solubility at } 30^{\circ} \mathrm{C} \\
\mathrm{g} / \mathrm{L}\end{array}$} & \multirow{2}{*}{$\begin{array}{l}\text { Cost } \\
\$ / \mathbf{k g}\end{array}$} & \multicolumn{2}{|c|}{ Concentration } \\
\hline & & & g/L & $\mathrm{mol} / \mathrm{L}$ \\
\hline $\mathrm{CaCl} 2$ & 1,020 & $\$ 9$ & 175 & 1.6 \\
\hline HCOONa & 655 & $\$ 13$ & 279 & 4.1 \\
\hline $\mathrm{KBr}$ & 594 & $\$ 20$ & 381 & 3.2 \\
\hline $\mathrm{LiBr}$ & 1,069 & $\$ 48$ & 191 & 2.2 \\
\hline $\mathrm{LiCl}$ & 607 & $\$ 56$ & 108 & 2.6 \\
\hline MgCl2 & 751 & $\$ 6$ & 143 & 1.5 \\
\hline $\mathrm{Na}\left(\mathrm{C}_{2} \mathrm{H}_{5} \mathrm{COO}\right)$ & 1,000 & $\$ 4$ & 389 & 4.1 \\
\hline $\mathrm{NaCl}$ & 318 & $\$ 3$ & 175 & 3.0 \\
\hline
\end{tabular}




\subsection{Analytical procedure}

MD and PRO samples were prepared and analyzed for total dissolved solids concentration according to Standard Methods (APHA, 2005). Samples were diluted and analyzed for anions with an ion chromatograph (Model ICS-90, Dionex, Sunnyvale, CA) and for cations with an inductively coupled plasma atomic emission spectrometer (ICP-AES) (Optima 5300 DV, PerkinElmer Inc., Waltham, MA). Total organic carbon for organic working fluids was analyzed using a carbon analyzer (Shimadzu, Kyoto, Japan).

\subsection{System modeling and cost estimation}

A series of mass and energy balances were used to determine system power outputs, system costs, and bleed ratios (salt specific). Bleed ratio is the fraction of the PRO feed stream (low concentration stream) that has to be diverted to the MD feed stream for recovery of salt and desalting of the PRO feed stream. The equations governing the cost and energy model are provided in the Supporting Information. A schematic drawing of a full-scale OHE is illustrated in Figure S1 in the Supporting Information.

Experimental results from PRO and MD bench scale experiments were used in the cost model, and include PRO water flux and RSF and MD water flux and rejection. Ideally, the PRO system would be operated at higher pressures and concentrations, allowing for higher power densities; however, it is expected that the relative ranking in terms of cost for different working fluids would be conserved at higher concentrations and pressures.

The parameters used in the model are summarized in Table 2. The MD recovery rate was referenced from literature [49]. At a feed and distillate temperature of $60{ }^{\circ} \mathrm{C}$ and $20{ }^{\circ} \mathrm{C}$, respectively, the maximum theoretical recovery in MD was determined to be $6.3 \%$ [49], therefore, a recovery of $6 \%$ was chosen for the model. MD membrane wetting was assumed negligible, thus the low concentration inlet and outlet stream are deionized water. PRO recoveries were referenced from FO manufacturer data [50]. The bleed ratio was determined by iterating until the inlet PRO feed concentration was $4 \mathrm{~g} / \mathrm{L}$. This PRO feed concentration was chosen because until this level it has minimal effect on the PRO driving force [3].

The costs considered in this model were PRO and MD membrane and module costs and salt costs, which are assumed to be the dominant system costs. Specific membrane and module costs for PRO and MD were referenced from reverse osmosis (RO) and MF manufacturing data, 
respectively [50-52]. A 35\% discount rate was applied to the quoted price to account for retail mark-up.

Table 2. Parameters used in the OHE energy and cost model. Specific membrane and module costs for PRO and MD were referenced from RO and MF manufacturing data, respectively. A $35 \%$ discount rate was applied to the quoted price to account for retail mark-up.

\begin{tabular}{|c|c|c|}
\hline \multicolumn{3}{|c|}{ System operating parameters } \\
\hline System size (gross power) & $1,000 \mathrm{~kW}$ & \\
\hline \multicolumn{3}{|c|}{ PRO operating inputs } \\
\hline PRO water recovery & $15 \%$ & [50] \\
\hline Applied hydraulic pressure (DS) & $2(300)$ & $\mathrm{MPa}(\mathrm{psi})$ \\
\hline PRO module pressure drop & $35(5)$ & $\mathrm{kPa}(\mathrm{psi})$ \\
\hline Feed temperature & 30 & ${ }^{\circ} \mathrm{C}$ \\
\hline Draw solution temperature & 30 & ${ }^{\circ} \mathrm{C}$ \\
\hline Draw solution concentration & Salt specific & $\mathrm{g} / \mathrm{L}$ \\
\hline Water flux & Salt specific & $\mathrm{L} / \mathrm{m}^{2}-\mathrm{hr}$ \\
\hline Salt flux & Salt specific & $\mathrm{g} / \mathrm{m}^{2}-\mathrm{hr}$ \\
\hline \multicolumn{3}{|c|}{ MD operating inputs } \\
\hline Water recovery & $6 \%$ & [49] \\
\hline PRO module pressure drop & $14(2)$ & $\mathrm{kPa}(\mathrm{psi})$ \\
\hline Feed temperature & $56 \pm 2$ & ${ }^{\circ} \mathrm{C}$ \\
\hline Distillate temperature & $25 \pm 1.5$ & ${ }^{\circ} \mathrm{C}$ \\
\hline Feed concentration & Salt specific & $\mathrm{g} / \mathrm{L}$ \\
\hline Water flux & Salt specific & $\mathrm{L} / \mathrm{m}^{2}-\mathrm{hr}$ \\
\hline Rejection & Salt specific & $\%$ \\
\hline \multicolumn{3}{|c|}{ Specific costs } \\
\hline Specific PRO membrane element cost & 11 & $\$ / \mathrm{m}^{2},[50]$ \\
\hline Specific PRO membrane vessel cost & 17 & $\$ / \mathrm{m}^{2},[52]$ \\
\hline Specific MD membrane element cost & 24 & $\$ / \mathrm{m}^{2},[52]$ \\
\hline Specific MD membrane vessel cost & 14 & $\$ / \mathrm{m}^{2},[52]$ \\
\hline \multicolumn{3}{|c|}{$\begin{array}{l}\text { Equipment efficiencies } \\
\end{array}$} \\
\hline ERD efficiency & $95 \%$ & \\
\hline Pump efficiency & $70 \%$ & \\
\hline \multicolumn{3}{|c|}{ Design constraint } \\
\hline PRO feed concentration & 4 & $\mathrm{~g} / \mathrm{L}$ or less \\
\hline
\end{tabular}

\section{Results and discussion}

PRO and MD bench scale experiments were performed with select salts as OHE working fluids. Working fluid performance was evaluated in terms of PRO water flux, power density, and reverse solute flux, and MD water flux, thermal efficiency, and potential for wetting.

\subsection{OLI modeling and working fluid selection}

The maximum solubility and corresponding osmotic pressure of solution and PVP of water in solution for the initial screening of salts are shown in Figure 8. Although some of the salts are 
highly soluble, they do not have high osmotic pressures - in general, solutions that have high osmotic pressures, have low PVP of water in solution [53]. The relationships between osmotic pressure and PVP can be explained by the equations describing the osmotic pressure of solution (van't Hoff equation) and PVP of water in solution (Raoult's law), in which water is the solvent. The osmotic pressure of a solution is defined by a modified van't Hoff equation and is a function of the ideal gas constant $(R)$, temperature of the solution $(T)$, activity of water $\left(\gamma_{w}\right)$, mole fraction of water $\left(\chi_{w}\right)$, and molar volume of water (V) (Eq. 13):

$$
\Pi=\frac{-R T \ln \left(\gamma_{w} \chi_{w}\right)}{V_{w}}
$$

The PVP of water in solution is defined by Raoult's law and is a function of the vapor pressure of pure water $\left(P^{o}\right)$ (temperature dependent), the activity of water $\left(\gamma_{w}\right)$, and the mole fraction of water $\left(\chi_{w}\right)$ (Equ 14):

$$
P^{*}=P^{o} \gamma_{w} \chi_{w}
$$

For example, when a given solution becomes more concentrated, the activity and mole fraction of water in the solution decreases, resulting in an increased osmotic pressure and decreased PVP. Therefore, working fluids that yield high PRO water fluxes most likely yield lower MD water fluxes.

Because the objective of the OHE is to produce energy, high PRO power densities must be obtained, and therefore, salts used in PRO must have high osmotic pressures. Following the initial screening, salts with osmotic pressures of $30 \mathrm{MPa}$ at saturation (close to the osmotic pressure of $\mathrm{NaCl}$ at saturation) or higher were chosen for investigation. These salts include potassium bromide $(\mathrm{KBr})$, sodium chloride $(\mathrm{NaCl})$, sodium formate $(\mathrm{HCOONa})$, sodium propionate $\left(\mathrm{Na}\left(\mathrm{C}_{2} \mathrm{H}_{5} \mathrm{COO}\right)\right)$, magnesium chloride $\left(\mathrm{MgCl}_{2}\right)$, calcium chloride $\left(\mathrm{CaCl}_{2}\right)$, lithium bromide ( $\mathrm{LiBr}$ ), and lithium chloride $(\mathrm{LiCl})$. Of the select salts, $\mathrm{NaCl}$ is the least soluble and $\mathrm{LiBr}, \mathrm{CaCl}_{2}$, and $\mathrm{Na}\left(\mathrm{C}_{2} \mathrm{H}_{5} \mathrm{COO}\right)$ are the most soluble.

Because the salts investigated in these experiments are at high concentrations, corrosion in the system is an important consideration. Corrosion can degrade pipes and turbo-machinery (e.g., pumps, turbines, heat exchangers, pressure exchangers) and reduce equipment lifetime. 
Furthermore, oxidized metals can deposit on the membranes and form scaling layers, thus decreasing PRO power density and possibly cause wetting of the MD membranes. Corrosion rates for the select salts at draw solution concentrations equivalent to 17.4 MPa of osmotic pressure with different metals (i.e., carbon steel, stainless steel 316, and stainless steel 304) are shown in Figure 9. Carbon steel was chosen because of its low cost. Stainless steel 304 and stainless steel 316 were chosen because of their resistance to corrosion. Titanium is another material with high resistance to corrosion; however, this metal is not available in the OLI Corrosion Analyzer database.
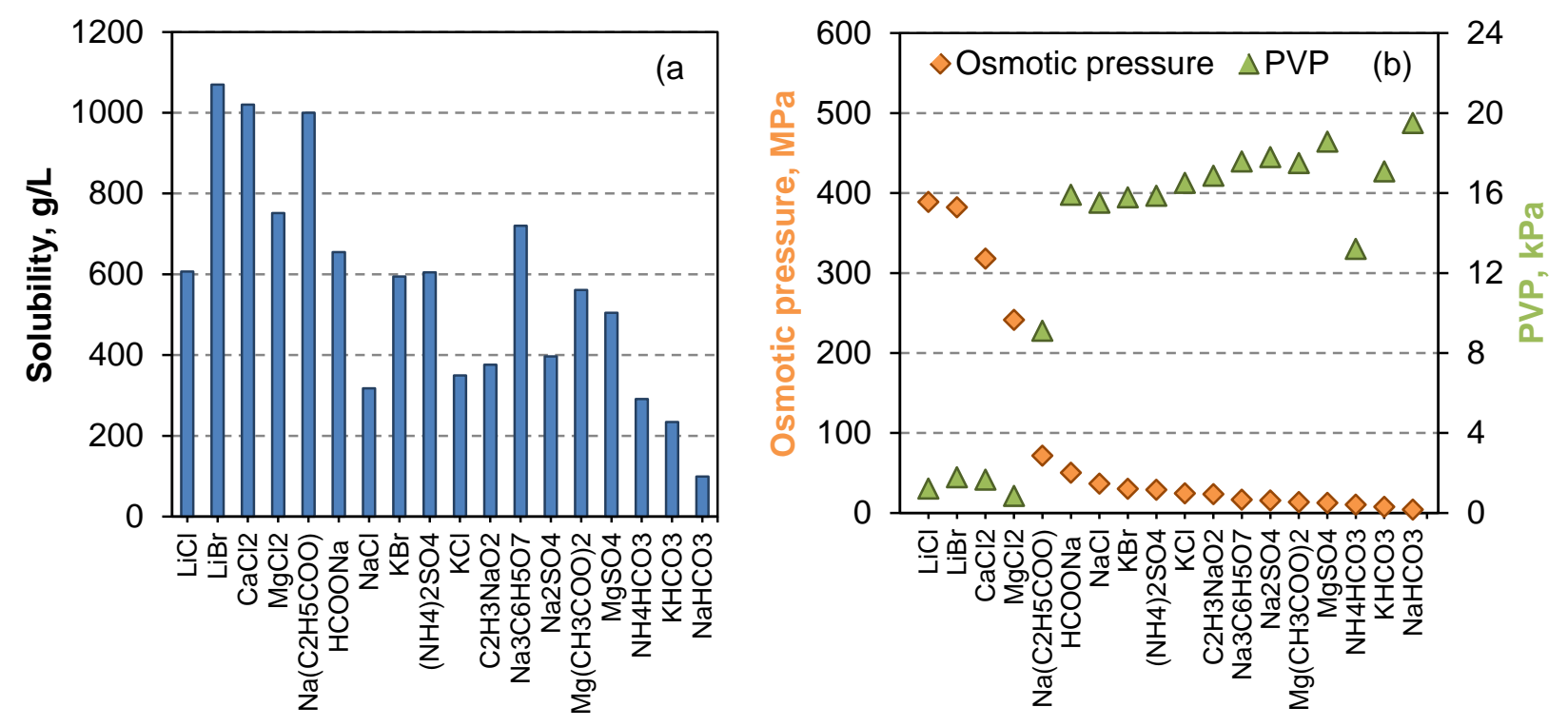

Figure 8. The (a) maximum solubility (at $30{ }^{\circ} \mathrm{C}$ ) for the select salts and their corresponding (b) osmotic pressure (at $30^{\circ} \mathrm{C}$ ) and PVP (at $60^{\circ} \mathrm{C}$ ) at saturation.

Stainless steel is a steel alloy enriched in chromium to increase oxidative corrosion resistance. Iron forms very brittle oxide films that easily detach and expose unoxidized metal. Conversely, chromium forms highly ductile oxide films that protect the underlying unoxidized metal. However, chloride ions are known to diffuse into the thin film of oxides and attack the underlying unpassivated steel [54]. Once this film is penetrated, pitting corrosion occurs [55]. Stainless steel 316 is enriched in molybdenum, which aids in decreasing chloride diffusion through the oxide layer. As a result, this alloy exhibits higher resistances to pitting corrosion. 


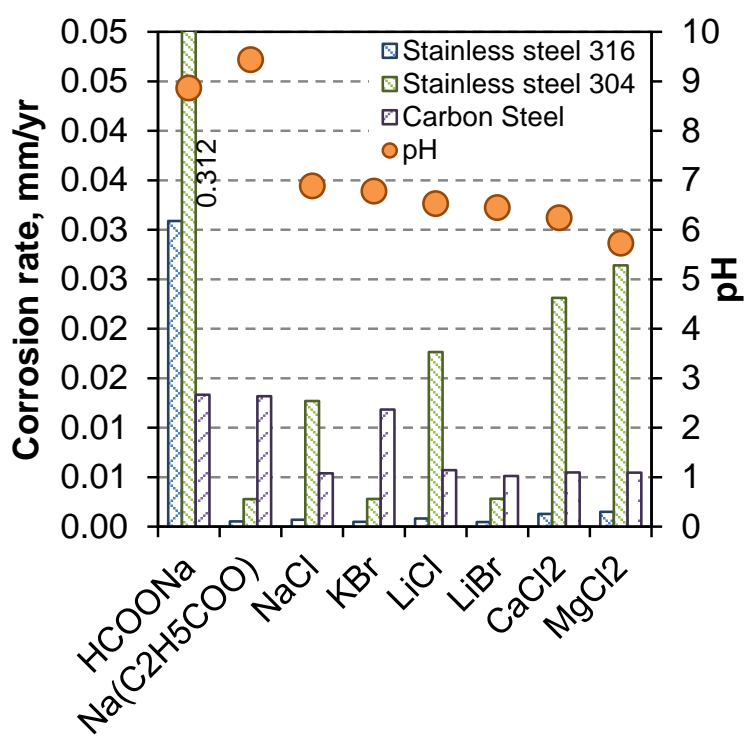

Figure 9. Corrosion rates and $\mathrm{pH}$ for select working fluids. Corrosion rates were calculated at draw solution concentrations equivalent to $17.4 \mathrm{MPa}$ of osmotic pressure.

Solution $\mathrm{pH}$ and chloride content are among the solution properties that most influence corrosion rates. For instance, $\mathrm{LiBr}$ has one of the lowest corrosion potentials, one of the lowest solution $\mathrm{pH}$, and is absent of chloride. Overall, stainless steel 316 is one of the least corrosive materials for all salts, with the exception of HCOONa, which has one of the highest pHs and has the highest corrosion rate of all salts. HCOONa is also the only salt for which carbon steel is the least corrosive of the three materials. In general, carbon steel (absence of oxide film barrier) is most influenced by solution $\mathrm{pH}$; the higher the $\mathrm{pH}$ of the solution, the higher the carbon steel corrosion rate; however, carbon steel is not sensitive to the chloride content of the working fluid. Conversely, the higher the chloride content in solution, the higher the corrosion rate for stainless steel 304. For example, stainless steel 304 had the highest corrosion rate for working fluids with chloride ions (i.e., $\mathrm{NaCl}, \mathrm{LiCl}, \mathrm{CaCl}_{2}, \mathrm{MgCl}_{2}$ ).

\subsection{Experimental results: PRO}

Water flux, power density, RSF, specific RSF, solute diffusivity coefficient (D), and permeability through the HTI TFC membrane (B) (calculated with Eq. 8) for the selected salts are shown in Figure 10. Although experiments were performed with the same osmotic pressure difference across the membrane (draw solution having osmotic pressure of 17.4 MPa), water flux ranged from 9.5 to $30 \mathrm{~L} / \mathrm{m}^{2}$-h and power density from 11.2 to $17.6 \mathrm{~W} / \mathrm{m}^{2}$. Of the investigated 
salts, HCOONa had the highest water flux and power density and $\mathrm{Na}\left(\mathrm{C}_{2} \mathrm{H}_{5} \mathrm{COO}\right)$ had the lowest water flux and power density.

The difference in water flux and power density can be explained by the difference in ICP, ECP, and/or solute permeability. Several studies have concluded that ICP is more dominant than ECP, which is considered negligible [3, 17, 32, 33]. Because the same membrane was used for all experiments, the membrane structural parameter can be assumed constant [19], and therefore, the difference in solute diffusivity between the draw solutions dictates the severity of ICP [19]. As a result, the difference in water flux is due to the difference in solute diffusivity $(D)$ and salt permeability (B).

Draw solution RSF ranged from 11.8 to $148 \mathrm{~g} / \mathrm{m}^{2}-\mathrm{h}$. $\mathrm{Na}\left(\mathrm{C}_{2} \mathrm{H}_{5} \mathrm{COO}\right)$ and HCOONa had the lowest RSF and specific RSF. Similar to water flux, RSF (Eq. 8) is a function of ICP (related to $D$ ), ECP (related to $k$ ), and solute permeability; however, in contrast to water flux, a clear trend can be observed between RSF, specific RSF, and salt permeability. For example, $\mathrm{KBr}$ has one of the highest salt permeabilities and one of the highest RSF, whereas $\mathrm{Na}\left(\mathrm{C}_{2} \mathrm{H}_{5} \mathrm{COO}\right)$ and HCOONa have the smallest salt permeability coefficients and the lowest RSF.

Salt permeability represents the diffusion of solutes in the membrane active layer and is dominated by the hydrated radius of the solute. From the Stokes-Einstein equation it can be derived that the hydrated radius of the solute is inversely proportional to its diffusivity [56]. Therefore, solute diffusivity is directly related to the hydrated radius of the solute and hence salt permeability. Achilli et al. also observed that ions with smaller hydration diameter, and thus higher diffusivity, exhibit higher RSF [19]. With the exception of the organic draw solutions, high diffusivities relate to high RSF. Similarly, solutes with ions of large hydration diameters relate to lower RSF. For example, $\mathrm{KBr}$ has the highest RSF, second highest diffusivity, and ions with two of the smallest hydration diameters (Table 3). However, the same trend between high diffusivity and high RSF does not apply to organic solutes. Organic compounds exhibit hydrophobic interactions with the carboxylic functional groups in negatively charged polymeric membranes [57]. Therefore, other forces might play a role in retarding diffusive transport through the membrane. 

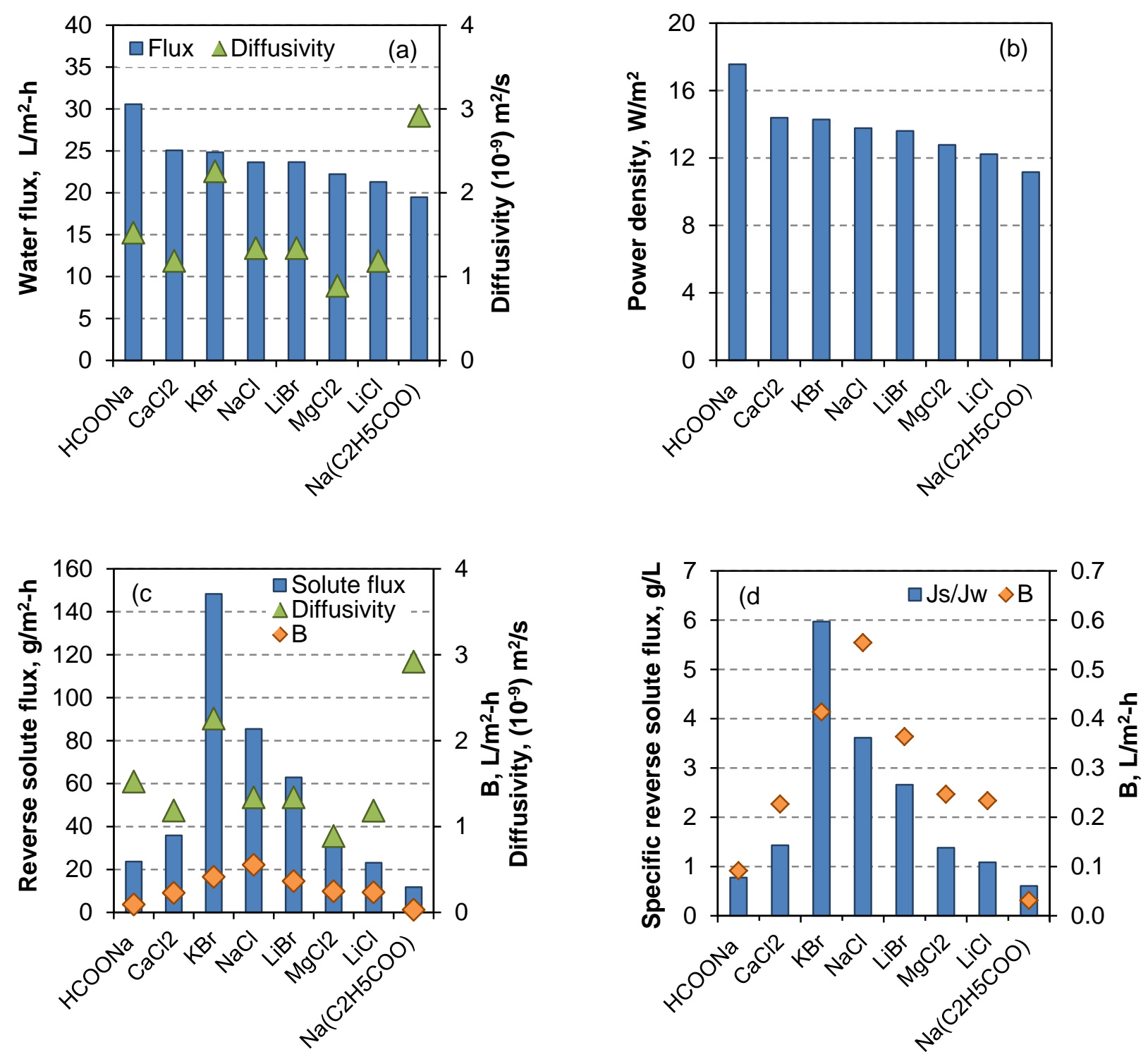

Figure 10. PRO (a) water flux, (b) power density, (c) reverse solute flux, and (d) specific reverse solute flux for select OHE working fluids. Solute diffusivity and permeability are also shown. PRO experiments operated at temperatures, flow rates, and applied hydraulic pressures (draw solution) of $30{ }^{\circ} \mathrm{C}, 0.5 \mathrm{~L} / \mathrm{min}$, and $2 \mathrm{MPa}(300 \mathrm{psi})$. The feed stream was deionized water and draw solution concentrations corresponded to osmotic pressures of $17.4 \mathrm{MPa}(\sim 2,500 \mathrm{psi})$. Thermodynamic properties and mass transfer coefficient for select draw solutions are also summarized in Table S1 of the Supporting Materials. On average of 5\% variation in water flux was observed during the experiments. 
Table 3. Hydrated diameters for different cations and anions [58, 59].

\begin{tabular}{lc}
\hline & Hydrated diameter, nm \\
\hline Anion & \\
\hline $\mathrm{Br}^{-}$ & 0.30 \\
$\mathrm{C}_{2} \mathrm{H}_{5} \mathrm{COO}^{-}$ & 0.50 \\
$\mathrm{Cl}^{-}$ & 0.30 \\
$\mathrm{HCOO}^{-}$ & 0.35 \\
\hline Cation & \\
\hline $\mathrm{Ca}^{+}$ & 0.60 \\
$\mathrm{~K}^{+}$ & 0.30 \\
$\mathrm{Li}^{+}$ & 0.60 \\
$\mathrm{Mg}_{2}^{+}$ & 0.80 \\
$\mathrm{Na}^{+}$ & 0.45 \\
\hline
\end{tabular}

Specific RSF values ranged from and 0.6 to $6 \mathrm{~g} / \mathrm{L}$. $\mathrm{KBr}, \mathrm{NaCl}$, and $\mathrm{LiBr}$ had the highest specific RSF and $\mathrm{LiCl}, \mathrm{MgCl}_{2}, \mathrm{CaCl}_{2}, \mathrm{Na}\left(\mathrm{C}_{2} \mathrm{H}_{5} \mathrm{COO}\right)$, and $\mathrm{HCOONa}$ had the lowest specific RSF. The specific RSF is a measurement of how much salt will need to be replenished in the draw solution, and in the OHE, it is an indicator of the bleed ratio (see section 3.7). Higher bleed ratio requires larger MD membrane area to reconcentrate the draw solution; therefore, salts with high specific RSF (i.e., $\mathrm{KBr}, \mathrm{NaCl}$, and $\mathrm{LiBr}$ ) can be detrimental to OHE system costs and viability.

\subsection{Experimental results: $\mathrm{MD}$}

Water flux, PVP of water in the MD bulk feed solution, and thermal efficiency for the MD experiments performed with the selected salts as the feed solutions are shown in Figure 11. The conductivity of the distillate stream (deionized water) decreased during the experiments, indicating that membranes rejected close to $100 \%$ of organic and inorganic feed solutes. The water flux for the different feed solutions ranged from 15 to $29 \mathrm{~L} / \mathrm{m}^{2}$-hr, where $\mathrm{LiCl}$ had the highest water flux. For most salts (excluding $\mathrm{LiCl}, \mathrm{CaCl}_{2}$, and $\mathrm{HCOONa}$ ) the water flux decreased with decreasing PVP of water in the feed. The viscosity, density, and heat capacity for the feed solutions at $56{ }^{\circ} \mathrm{C}$ were evaluated (Table S2 in the Supporting Information); however, no clear correlations between the thermodynamic properties, PVP, and water flux could be found. 

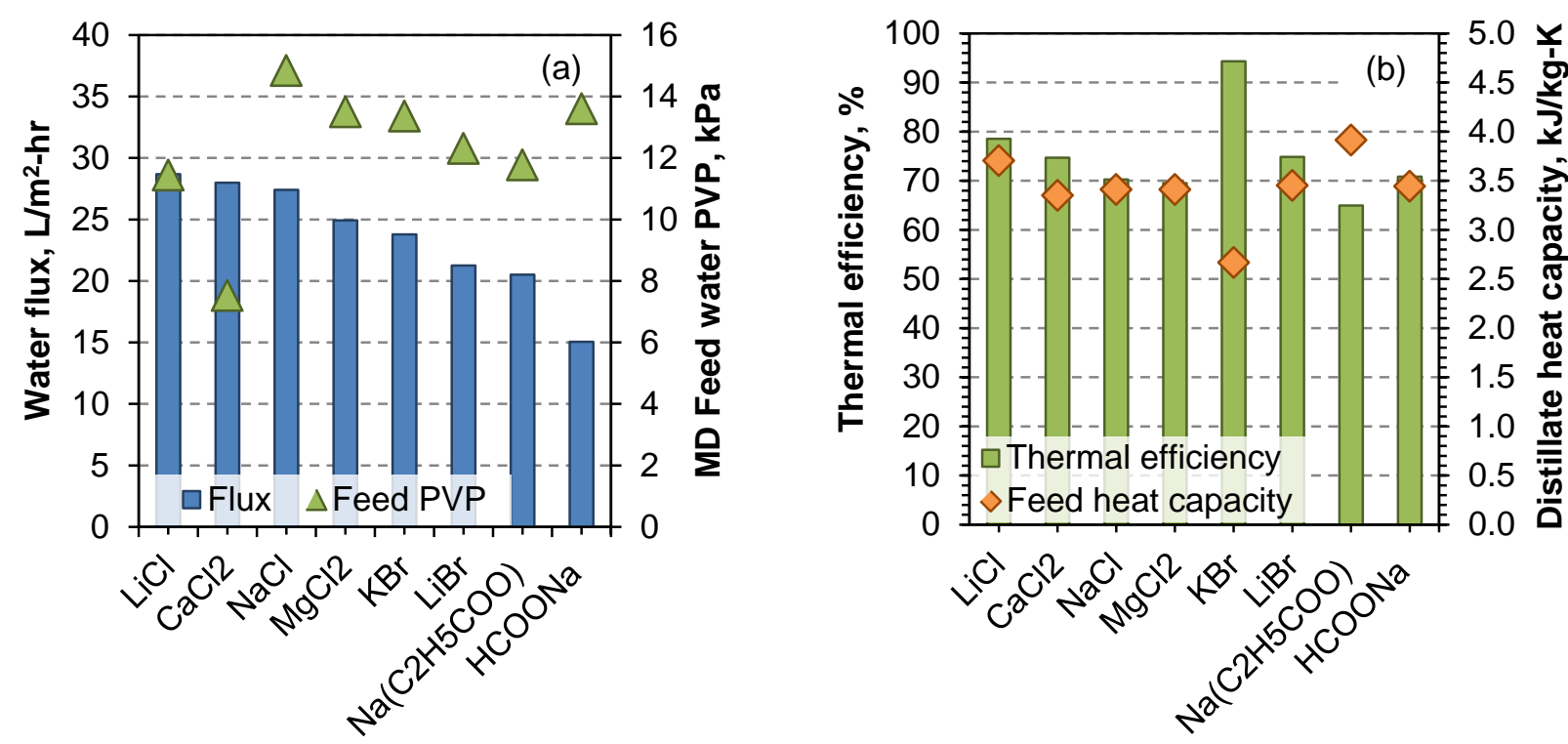

Figure 11. MD (a) water flux and feed water PVP, and (b) thermal efficiency and distillate heat capacity. MD feed and distillate stream temperatures were $56 \pm 1.6^{\circ} \mathrm{C}$ and $24 \pm 2{ }^{\circ} \mathrm{C}$, respectively, and stream velocities were kept constant at $1 \mathrm{~L} / \mathrm{min}$. The distillate stream was deionized water and feed solution concentrations correspond to osmotic pressures of $17.4 \mathrm{MPa}(\sim 2,500 \mathrm{psi})$. The thermodynamic properties for the MD feed solutions at their respective concentrations are summarized in Table S2 of the Supporting Information. On average of 5\% variation in water flux was observed during the experiments.

The thermal efficiencies of the solutions ranged from 65 to 94\%, with $\mathrm{KBr}$ having the highest thermal efficiency and $\mathrm{Na}\left(\mathrm{C}_{2} \mathrm{H}_{5} \mathrm{COO}\right)$ having the lowest thermal efficiency. The thermal efficiency of the MD distillate stream decreased with decreasing water flux. $\mathrm{Na}\left(\mathrm{C}_{2} \mathrm{H}_{5} \mathrm{COO}\right)$ had the lowest thermal efficiency, because of its high heat capacity and low water flux. Because thermal efficiency corresponds to the ratio of water flux to the total heat flux, it is an important parameter in the OHE. Working fluids with high thermal efficiencies are more effective in utilizing heat for their regeneration.

Although some of the investigated salts have desirable characteristics in PRO or MD (i.e., power density, specific RSF, water flux), they had undesirable characteristics in the other process. For example, HCOONa has the highest PRO power density and one of the lowest specific RSF; however, it had the lowest MD water flux. $\mathrm{Na}\left(\mathrm{C}_{2} \mathrm{H}_{5} \mathrm{COO}\right)$ had a low PRO power density and low MD water flux, but had the lowest specific RSF. $\mathrm{CaCl}_{2}$ on the other hand performed well in both PRO and MD - it had a high power density, low specific RSF, and high MD water flux. When evaluating individual experimental results, there is no obvious relation between performance in PRO and MD and it is difficult to draw a definitive conclusion about 
which salt is best suited as an OHE working fluid. Therefore, a system model was developed and experimental results were used as inputs to evaluate system net power output and electricity generation costs for each of the working fluids.

\subsection{Cost modeling results and working fluid selection}

System capital costs, net power output, and electricity generation costs for the selected working fluids are shown in Figure 12. The total costs range from 5.9 to 10.1 million dollars and net electrical power outputs range from 150 to $450 \mathrm{~kW}$ (1 MW gross power). The total electricity generation costs range from $\$ 7.72$ to $\$ 1.65$ per $\mathrm{kWh}$. It is important to note that electricity generation costs are higher than what would be expected because of the low PRO draw solution hydraulic pressures (2 MPa or $300 \mathrm{psi}$ ), which resulted in low PRO power densities. In the future, operating the PRO process with membranes that will be able to tolerate higher pressure will enable operation at higher pressure, higher power density, and therefore lower electricity generation cost. $\mathrm{KBr}$ is the most expensive working fluid-it had one of the lowest net energy generation and highest system costs. $\mathrm{CaCl}_{2}$ is the least expensive working fluid-it had one of the highest net energy productions and lowest system costs. $\mathrm{CaCl}_{2}$ had the second highest power density, a low specific RSF, and the second highest MD water flux. $\mathrm{MgCl}_{2}, \mathrm{Na}\left(\mathrm{C}_{2} \mathrm{H}_{5} \mathrm{COO}\right), \mathrm{LiCl}$, and HCOONa have the lowest electricity generation costs ranging from 1.7 to $2.1 \$ / \mathrm{kWh}$-these salts also had some of the lowest specific RSF and highest net energy production.

Salts with high RSF had high MD membrane costs, low net power outputs, and high electricity generation costs. This is due to the additional MD membrane area and pumping energy needed for recovering the salts from the PRO feed stream. For example, $\mathrm{KBr}$ has the highest RSF, the lowest net power output, and the highest system capital and electricity generation costs. The largest cost contributor to $\mathrm{KBr}$ is the additional MD membrane area needed to replenish the PRO draw solution, and additional pumping energy needed to replenish the draw solution substantially lowers system net power outputs. $\mathrm{NaCl}$ and $\mathrm{LiBr}$ also have high specific RSF, high additional MD membrane costs, and low net power outputs, thus resulting in high electricity generation costs. 

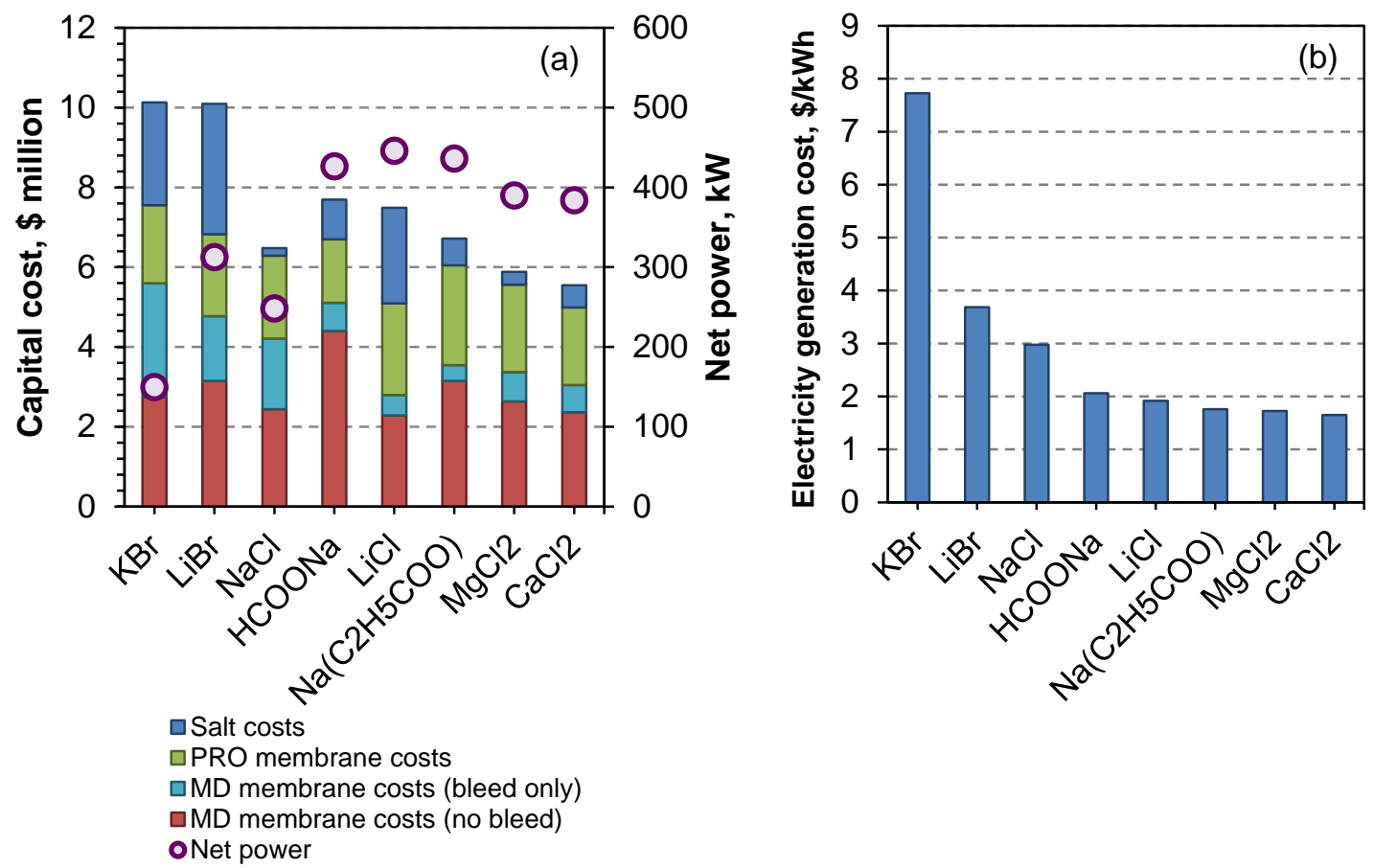

Figure 12. (a) Capital costs and net power and (b) electricity generation costs for a $1 \mathrm{MW}$ OHE system for select working fluids using PRO and MD experimental data. PRO experiments were conducted at temperatures and applied hydraulic pressures of $30{ }^{\circ} \mathrm{C}$ and $2 \mathrm{MPa}(300 \mathrm{psi})$, respectively. MD feed and distillate stream temperatures were $24 \pm 2{ }^{\circ} \mathrm{C}$ and $56 \pm 1.6{ }^{\circ} \mathrm{C}$, respectively, and the cross flow velocities were kept constant at $1 \mathrm{~L} / \mathrm{min}$. Working fluid concentrations correspond to osmotic pressures of 17.4 MPa ( 2,500 psi).

MD membrane cost is the largest contributor to system cost for all the salts tested. The costs for MD membranes (without bleeding of PRO feed) ranged from 2.4 to 4.4 million dollars and the costs for PRO membranes ranged from 1.6 to 2.5 million dollars-MD membrane total cost is nearly twice as high as total PRO membrane costs. Although water fluxes for MD and PRO were relatively similar (with the exception of HCOONa), the specific cost for MD membrane modules is nearly 36\% higher than the costs for PRO membrane modules (Table 2). The total cost for MD membranes (i.e., membranes for working fluid regeneration and additional membranes for bleeding) is by far the greatest contributor to capital cost; therefore, when developing commercial scale OHE, attention must be given to optimizing the draw solution regeneration system. Selecting a working fluid with high MD water fluxes and low PRO specific RSF is paramount to realizing reduced capital costs for the regeneration system and subsequently for the OHE. 
The working fluid costs vary significantly among the different salts, ranging from $\$ 200,000$ to $\$ 3.3$ million dollars for a $1 \mathrm{MW}$ (gross power) system. A system with $\mathrm{LiBr}$ as the working fluid has one of the highest specific salt costs (48 \$/kg) and the highest total working fluid cost. However, working fluids with high specific salt costs do not necessarily result in high system capital costs or high electricity generation costs. For example, although $\mathrm{LiCl}$ has the highest specific salt cost (56 \$/kg), $\mathrm{LiCl}$ can generate higher osmotic pressures at lower concentrations; thus, less salt is needed. On the other hand, $\mathrm{NaCl}$ is one of the most abundant salts and has the lowest specific and total salt costs; however, a system with $\mathrm{NaCl}$ as the working fluid does not have the lowest capital costs or electricity generation costs because of the high RSF. While salt costs were not always the largest line-item for the continuous electricity generation OHE, these costs would be more significant if the system were used for energy storage.

Based on the results, it becomes apparent that several performance criteria are of importance when evaluating OHE working fluids, and although electricity generation costs are a key consideration, other performance criteria, including potential for system corrosion and thermal efficiency, must be considered. The performance criteria for each of the selected working fluids is summarized in Table 4. The relative performance of the working fluids for each of the different criteria was assessed in terms of adequate ( $\square$ ) and inadequate ( $\square$ rating. If the working fluid performed better than the average for the select performance criteria, the salts were ranked adequate ( $\square$; otherwise, they were marked inadequate ( $\square$ ). Salts are ranked from low electricity generation costs $\left(\mathrm{CaCl}_{2}\right)$ to high electricity generation costs. It can be conclude that working fluids with low RSF resulted in good net energy production and low electricity generation costs. Also, salts with the lowest electricity generation costs (i.e., $\mathrm{CaCl}_{2}, \mathrm{MgCl}_{2}, \mathrm{Na}\left(\mathrm{C}_{2} \mathrm{H}_{5} \mathrm{COO}\right.$ ), $\mathrm{LiCl}$, and $\mathrm{HCOONa}$ ) had low specific salt costs and had good MD water fluxes. Interestingly, although $\mathrm{CaCl}_{2}, \mathrm{MgCl}_{2}$, and $\mathrm{Na}\left(\mathrm{C}_{2} \mathrm{H}_{5} \mathrm{COO}\right)$ were not the best working fluids for PRO or MD, they had some of the lowest $\mathrm{OHE}$ electricity generation costs-confirming that several performance criteria play an important role in OHE electricity generation costs. Although HCOONa had one of the lowest RSF, it has one of the highest corrosion potentials and lowest thermal efficiency. Salts with high corrosion rates have a higher potential for equipment degradation, which can result in increased capital and operating costs. Likewise, working fluids with low thermal efficiencies will result in lowered system efficiencies. Of the working fluids evaluated, only $\mathrm{CaCl}_{2}$ performed well in each category. 
Table 4. Performance criteria for different working fluids. If the working fluid performed better than the average for the select performance criteria, the salts were ranked adequate (口); otherwise, they were marked inadequate ( $\square$ ). Salts are ranked from low electricity generation costs $\left(\mathrm{CaCl}_{2}\right)$ to high electricity generation costs.

\begin{tabular}{|c|c|c|c|c|c|c|c|c|}
\hline & $\begin{array}{c}\text { PRO } \\
\text { power } \\
\text { density }\end{array}$ & RSF & $\begin{array}{l}\text { MD water } \\
\text { flux }\end{array}$ & $\begin{array}{l}\text { MD thermal } \\
\text { efficiency }\end{array}$ & $\begin{array}{l}\text { Corrosion } \\
\text { rate }\end{array}$ & $\begin{array}{c}\text { Net } \\
\text { power }\end{array}$ & $\begin{array}{l}\text { Specific } \\
\text { salt cost }\end{array}$ & $\begin{array}{l}\text { Electricity } \\
\text { generation } \\
\text { costs }\end{array}$ \\
\hline $\mathrm{CaCl}_{2}$ & $\square$ & $\square$ & $\square$ & $\square$ & $\square$ & $\square$ & $\square$ & $\square$ \\
\hline $\mathrm{MgCl}_{2}$ & $\square$ & $\square$ & $\square$ & $\square$ & $\square$ & $\square$ & $\square$ & $\square$ \\
\hline $\mathrm{Na}\left(\mathrm{C}_{2} \mathrm{H}_{5} \mathrm{COO}\right)$ & $\square$ & $\square$ & $\square$ & $\square$ & $\square$ & $\square$ & $\square$ & $\square$ \\
\hline $\mathrm{LiCl}$ & $\square$ & $\square$ & $\square$ & $\square$ & $\square$ & $\square$ & $\square$ & $\square$ \\
\hline HCOONa & $\square$ & $\square$ & $\square$ & $\square$ & $\square$ & $\square$ & $\square$ & $\square$ \\
\hline $\mathrm{NaCl}$ & $\square$ & $\square$ & $\square$ & $\square$ & $\square$ & $\square$ & $\square$ & $\square$ \\
\hline $\mathrm{LiBr}$ & $\square$ & $\square$ & $\square$ & $\square$ & $\square$ & $\square$ & $\square$ & $\square$ \\
\hline $\mathrm{KBr}$ & $\square$ & $\square$ & $\square$ & $\square$ & $\square$ & $\square$ & $\square$ & $\square$ \\
\hline
\end{tabular}

\section{Conclusions}

The performance of potential working fluids for the closed loop OHE was experimentally evaluated in both PRO and MD. HCOONa and $\mathrm{CaCl}_{2}$ outperformed $\mathrm{NaCl}$ in terms of PRO power density and specific RSF, and $\mathrm{LiCl}$ and $\mathrm{CaCl}_{2}$ outperformed $\mathrm{NaCl}$ in terms of $\mathrm{MD}$ water flux. Working fluids with low RSF lead to lower pumping energy and MD membrane area, which resulted in low capital costs, high net power generation, and low electricity generation costs. Of the select salts, $\mathrm{CaCl}_{2}, \mathrm{MgCl}_{2}$, sodium propionate, and $\mathrm{LiCl}$ resulted in the lowest $\mathrm{OHE}$ electricity generation costs and had the lowest potential for corrosion. $\mathrm{CaCl}_{2}$ was the only working fluid that performed well for each of the performance criteria (i.e., low specific salt costs and RSF, and high PRO power density, MD water flux, MD thermal efficiencies, and net power generation) - consequently, these salts had the lowest electricity generation costs. Yet, the electricity generation cost of a closed-loop OHE under the tested conditions is much higher than the current cost of most renewable energy sources. In the future, operating the PRO process with membranes that will be able to tolerate higher pressures will enable operation at higher pressure, higher power density, and therefore lower electricity generation cost. Because several factors contribute to generation costs, an ideal salt would combine high power densities, low RSF, low salt costs, high MD water fluxes and thermal efficiencies, and low potential for equipment corrosion. Results from this study can also be impactful in identifying ideal working fluids for closed-loop FO-MD. 


\section{Acknowledgements}

The authors would like to thank US Department of Energy, Advanced Research Projects Agency-Energy (ARPA-e) Award \#0670-3228 and EPA-STAR for the financial support of the research. The authors would also like to acknowledge Mr. Tani Cath and Mr. Mike Veres for their technical support in bench scale system fabrication and the control system design, and Ms. Katie Schumacher and Mr. Curtis Weller for their contributions in the lab. Special thanks to Keith Lampi and Edward Beaudry (HTI) for providing membranes and technical support.

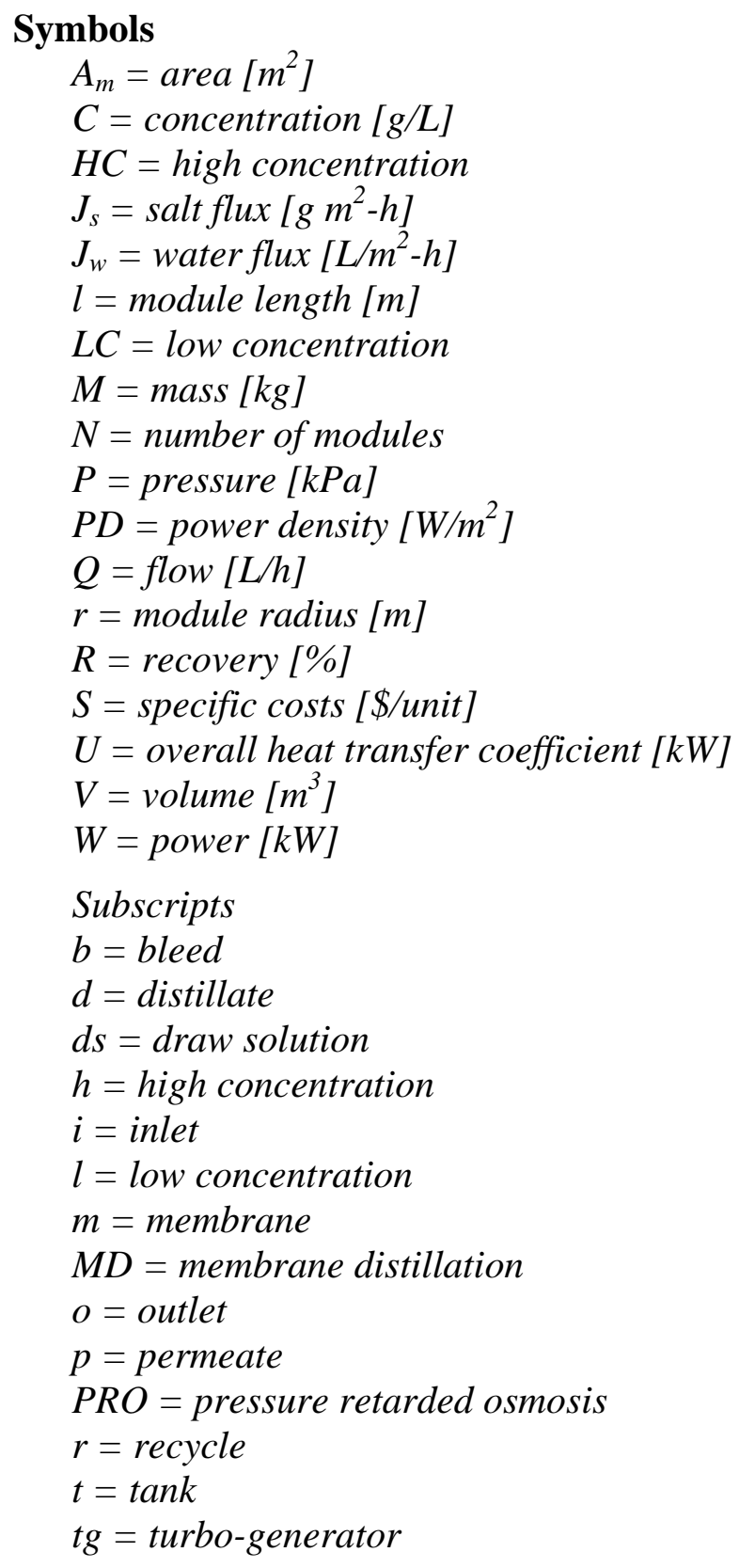




\section{References}

[1] S. Loeb, R.S. Norman, Osmotic power plants, Science 189 (1975) 654-655.

[2] Y.C. Kim, M. Elimelech, Potential of osmotic power generation by pressure retarded osmosis using seawater as feed solution: Analysis and experiments, Journal of Membrane Science 429 (2013) 330-337.

[3] A. Achilli, T.Y. Cath, A.E. Childress, Power generation with pressure retarded osmosis: An experimental and theoretical investigation, Journal of Membrane Science 343 (2009) 42-52.

[4] S. Chou, R. Wang, L. Shi, Q. She, C. Tang, A.G. Fane, Thin-film composite hollow fiber membranes for pressure retarded osmosis (PRO) process with high power density, Journal of Membrane Science 389 (2012) 25-33.

[5] A. Achilli, J.L. Prante, N.T. Hancock, E.B. Maxwell, A.E. Childress, Experimental results from RO-PRO: A next generation system for low-energy desalination, Environmental Science \& Technology 48 (2014) 6437-6443.

[6] A. Altaee, G. Zaragoza, A. Sharif, Pressure retarded osmosis for power generation and seawater desalination: Performance analysis, Desalination 344 (2014) 108-115.

[7] T. Thorsen, T. Holt, The potential for power production from salinity gradients by pressure retarded osmosis, Journal of Membrane Science 335 (2009) 103-110.

[8] W.R. Thelin, E. Siversten, T. Holt, G. Brekke, Natural organic matter fouling in pressure retarded osmosis, Journal of Membrane Science 438 (2013) 46-56.

[9] N.Y. Yip, M. Elimelech, Influence of Natural Organic Matter Fouling and Osmotic Backwash on Pressure Retarded Osmosis Energy Production from Natural Salinity Gradients, Environmental Science \& Technology 47 (2013) 12607-12616.

[10] S. Loeb (1980) Method and apparatus for generating power utilizing pressure-retarded osmosis, US Patent 4193267 A.

[11] R.L. McGinnis, J.R. McCutcheon, M. Elimelech, A novel ammonia-carbon dioxide osmotic heat engine for power generation, Journal of Membrane Science 305 (2007) 1319.

[12] S. Lin, N.Y. Yip, T.Y. Cath, C.O. Osuji, M. Elimelech, Hybrid pressure retarded osmosis-membrane distillation system for power generation from low-grade heat: Thermodynamic analysis and energy efficiency, Environmental Science \& Technology 48 (2014) 5306-5313. 
[13] L.M. Camacho, L. Dumee, J. Zhang, J.-D. Li, M. Duke, J. Gomez, S. Gray, Review: Advances in membrane distillation for water desalination and purification applications, Water 5 (2013) 94-196.

[14] K.W. Lawson, D.R. Lloyd, Membrane distillation, Journal of Membrane Science 124 (1997) 1-25.

[15] Department of Energy, Waste heat recovery: Technology and opportunities in U.S. industry, 2008, Department of Energy, Washington, D.C. http://www1.eere.energy.gov/manufacturing/intensiveprocesses/pdfs/waste_heat_recover y.pdf

[16] K.L. Hickenbottom, J. Vanneste, M. Elimelech, T.Y. Cath, Assessing the current state of commercially available membranes and spacers for energy production with PRO: An experimental investigation, Desalination, in press (2016) doi:10.1016/j.desal.2015.1009.1029.

[17] A. Achilli, T.Y. Cath, A.E. Childress, Power generation with pressure retarded osmosis: An experimental and theoretical investigation, J. Membr. Sci. 343 (2009) 42-52.

[18] T.Y. Cath, M. Elimelech, J.R. McCutcheon, R.L. McGinnis, A. Achilli, D. Anastasio, A.R. Brady, A.E. Childress, I.V. Farr, N.T. Hancock, J. Lampi, L.D. Nghiem, M. Xie, N.Y. Yip, Standard methodology for evaluating membrane performance in osmotically driven membrane processes, Desalination 312 (2013) 31-38.

[19] A. Achilli, T.Y. Cath, A.E. Childress, Selection of inorganic-based draw solutions for forward osmosis applications, Journal of Membrane Science 364 (2010) 233-241.

[20] R.W. Holloway, R. Maltos, J. Vanneste, T.Y. Cath, Mixed draw solutions for improved forward osmosis performance, Journal of Membrane Science 491 (2015) 121-131.

[21] G. Han, J. Zuo, C. Wan, T.-S. Chung, Hybrid pressure retarded osmosis-membrane distillation (PRO-MD) process for osmotic power and clean water generation, Environmental Science Water Research and Technology 1 (2015) 507-515.

[22] G. Han, Q. Ge, T.-S. Chung, Conceptual demonstration of novel closed-loop pressure retarded osmosis process for sustainable osmotic energy generation, Applied Energy 132 (2014) 383-393.

[23] A.P. Straub, N.Y. Yip, M. Elimelech, Raising the bar: Increased hydraulic pressure allows unprecedented high power densities in pressure-retarded osmosis, Environmental Science \& Technology Letters 1 (2013) 55-59.

[24] J.R. McCutcheon, R.L. McGinnis, M. Elimelech, Desalination by ammonia-carbon dioxide forward osmosis: Influence of draw and feed solution concentrations on process performance, Journal of Membrane Science 278 (2006) 114-123. 
[25] J.R. McCutcheon, R.L. McGinnis, M. Elimelech, A novel ammonia-carbon dioxide forward (direct) osmosis desalination process, Desalination 174 (2005) 1-11.

[26] S. Zhao, L. Zou, Relating solution physicochemical properties to internal concentration polarization in forward osmosis, Journal of Membrane Science 379 (2011) 459-467.

[27] K.S. Bowden, A. Achilli, A.E. Childress, Organic ionic salt draw solutions for osmotic membrane bioreactors, Bioresource Technology 122 (2012) 207-216.

[28] U.J. Bharwada, I.V. Farr, Use of novel draw solutions and combinations therof to improve performance of a forward osmosis system and process, US 20130256228 A1 Oct. 3, 2013.

[29] M.M. Ling, T.-S. Chung, Desalination process using super hydrophilic nanoparticles via forward osmosis integrated with ultrafiltration regeneration, Desalination 278 (2011) 194-202.

[30] M.C. Garcia-Payo, M.A. Izquierdo-Gil, C. Fernandez-Pineda, Wetting study of hydrophobic membranes via liquid entry pressure measurements with aqueous alcohol solutions, Journal of Colloid and Interface Science 230 (2000) 420-431.

[31] E. Shaulsky, C. Boo, S. Lin, M. Elimelech, Membrane-Based Osmotic Heat Engine with Organic Solvent for Enhanced Power Generation from Low-Grade Heat, Environmental Science \& Technology 49 (2015) 5820-5827.

[32] J.R. McCutcheon, M. Elimelech, Influence of concentrative and dilutive internal concentration polarization on flux behavior in forward osmosis, Journal of Membrane Science 284 (2006) 237-247.

[33] K.L. Lee, R.W. Baker, H.K. Lonsdale, Membrane for power generation by pressure retarded osmosis, Journal of Membrane Science 8 (1981) 141-171.

[34] M. Elimelech, S. Bhattacharjee, A novel approach for modeling concentration polarization in crossflow membrane filtration based on the equivalence of osmotic pressure model and filtration theory, Journal of Membrane Science 145 (1998) 223-241.

[35] N.Y. Yip, A. Tiraferri, W.A. Phillip, J.D. Schiffman, L.A. Hoover, Y.C. Kim, M. Elimelech, Thin-film composite pressure retarded osmosis membranes for sustainable power generation from salinity gradients, Environmental Science and Technology 45 (2011) 4360-4369.

[36] C.P. Koutsou, S.G. Yiantsios, A.J. Karabelas, A numerical and experimental study of mass transfer in spacer-filled channels: Effects of spacer geometrical characteristics and Schmidt number, Journal of Membrane Science 326 (2009) 234-251. 
[37] C.P. Koutsou, S.G. Yiantsios, A.J. Karabelas, Direct numerical simulation of flow in spacer-filled channels: Effect of spacer geometrical characteristics, Journal of Membrane Science 291 (2007) 53-69.

[38] G. Schock, A. Miguel, Mass transfer and pressure loss in spiral wound modules, Desalination 64 (1987) 339-352.

[39] N.Y. Yip, M. Elimelech, Performance limiting effects in power generation from salinity gradients by pressure retarded osmosis, Environmental Science \& Technology 45 (2011) 10273-10282.

[40] R.W. Schofield, A.G. Fane, C.J.D. Fell, R. Macoun, Factors affecting flux in membrane distillation, Desalination 77 (1990) 279-294.

[41] L. Martinez-Diez, M.I. Vazquez-Gonzalez, Temperature and concentration polarization in membrane distillation of aqueous salt solutions, Journal of Membrane Science 156 (1999) 265-273.

[42] M. Qtaishat, T. atsuura, B. Kruczek, M. Khayet, Heat and mass transfer in direct contact membrane distillation, Desalination 219 (2008) 272-292.

[43] A. Alkhudhiri, Membrane distillation: A comprehensive review, Desalination 287 (2012) 2-18.

[44] K.L. Hickenbottom, T.Y. Cath, Sustainable operation of membrane distillation for enhancement of mineral recovery from hypersaline solutions, Journal of Membrane Science 454 (2014) 426-435.

[45] C.R. Martinetti, A.E. Childress, T.Y. Cath, High recovery of concentrated RO brines using forward osmosis and membrane distillation, Journal of Membrane Science 331 (2009) 31-39.

[46] T.Y. Cath, V.D. Adams, A.E. Childress, Experimental study of desalination using direct contact membrane distillation: a new approach to flux enhancement, Journal of Membrane Science 228 (2004) 5-16.

[47] Y.C. Kim, Y. Kim, D. Oh, K.H. Lee, Experimental Investigation of a Spiral-Wound Pressure-Retarded Osmosis Membrane Module for Osmotic Power Generation, Environmental Science \& Technology 47 (2013) 2966-2973.

[48] E.L. Cussler, Diffusion: Mass transfer in fluid systems, 2nd, Cambridge University Press, New York, NY, 1997, 9780521564779.

[49] S. Lin, N.Y. Yip, M. Elimelech, Direct contact membrane distillation with heat recovery: Thermodynamic insights from module scale modeling, Journal of Membrane Science 453 (2014) 498-515. 
[50] HTI, FO element data sheet 101214, Corvallis, OR, 2014. Personal Communication.

[51] AMI membranes - Ultrafiltration membranes, 2015, http://www.wateranywhere.com/product_info.php?products_id=148

[52] Water Filters FAST, Protec membrane housing, 2015, http://www.waterfiltersfast.com/Protec-PRO-8-1200-SP-3-8-x-120-FRP-1200-PSI-SP15V-Protec-Membrane-Housing_p_2912.html

[53] L. Mariah, C.A. Buckley, C.J. Brouckaert, E. Curcio, E. Drioli, D. Jaganyi, D. Ramjugernath, Membrane distillation of concentrated brines-Role of water activities in the evaluation of driving force, Journal of Membrane Science 280 (2006) 937-947.

[54] N. Sridhar, C.S. Brossia, D.S. Dunn, A. Anderko, Predicting localized corrosion in seawater cooling systems, Proceedings of the CORROSION 2002, Denver, Colorado, April 7-11, 2002.

[55] K. Midander, Metal release from powder particles in synthetic biological media, Royal Institute of Technology, School of Industrial Engineering and Management, Department of Materials Science and Engineering, Licentiate thesis, Stockholm, Sweden (2006).

[56] M. Mulder, Basic principles of membrane technology, Kluver Academic Publishers, Dordrecht, The Netherlands, 1991, 9780792342472.

[57] A. Childress, M. Elimelech, Effect of solution chemistry on the surface charge of polymeric reverse osmosis and nanofiltration membranes, Journal of Membrane Science 119 (1996) 253-268.

[58] J. Kielland, Individual activity coefficients of ions in aqueous solutions, Journal of the Chemical American Society 59 (1937) 1675-1678.

[59] J. Bormann, O.P. Hamill, B. Sakmann, Mechanism of anion permeation through channels gated by glycine and gamma-aminobutyric acid in mouse cultured spinal neurones, The Journal of Physiology 385 (1987) 243-286. 


\section{Graphical abstract}

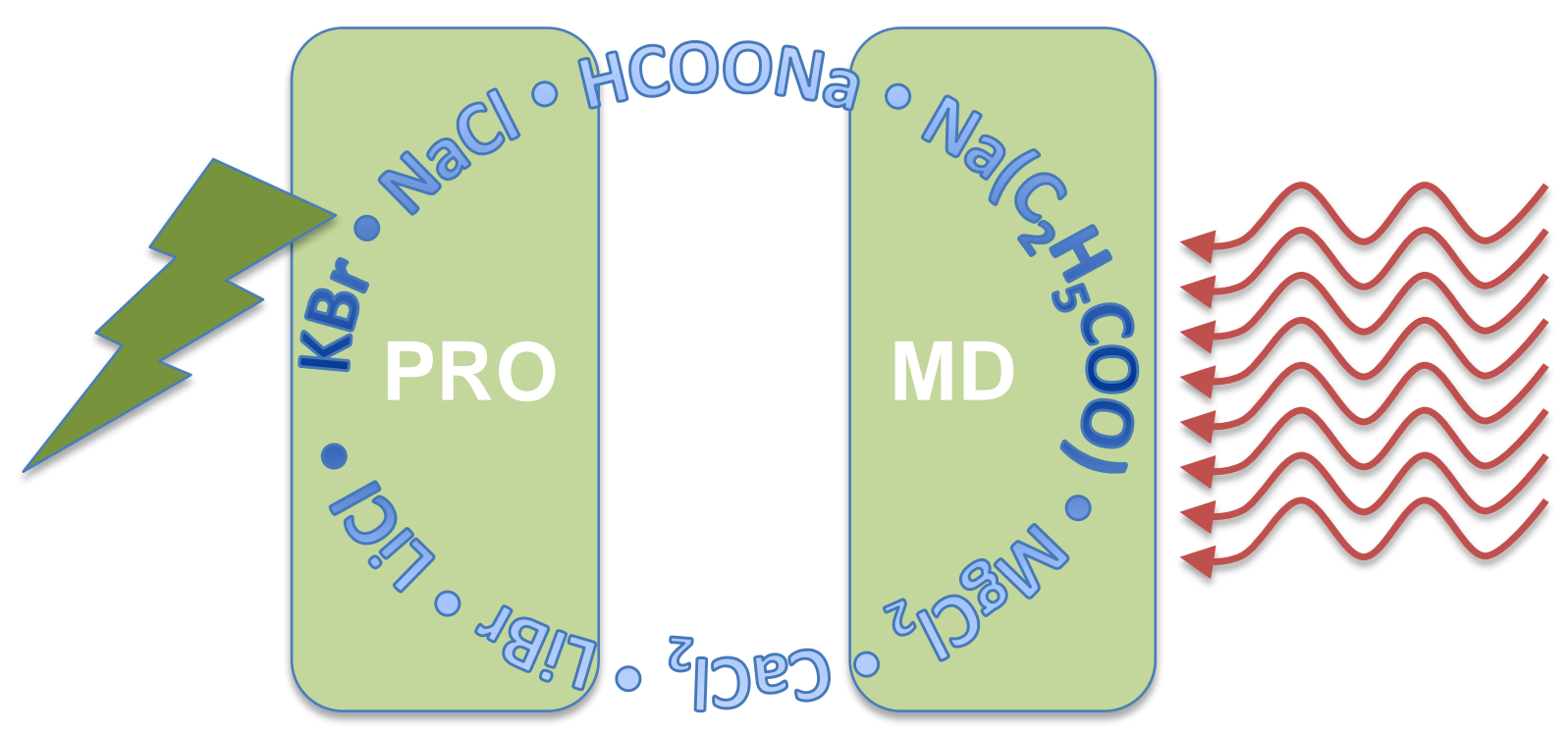

